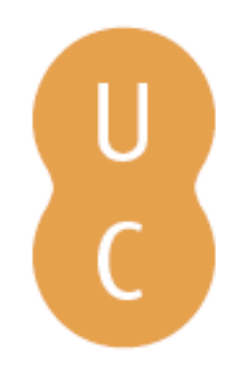

\title{
pommalina
}

\section{Regimes políticos nas Histórias de Heródoto: o "Diálogo dos Persas" (3. 80-82)}

\author{
Autor(es): $\quad$ Soares, Carmen
}

Publicado por: Imprensa da Universidade de Coimbra; Annablume

URL

persistente: URI:http://hdl.handle.net/10316.2/40808

DOI: $\quad$ DOl:https://doi.org/10.14195/978-989-26-1280-5_2

Accessed : $\quad$ 26-Apr-2023 12:17:39

A navegação consulta e descarregamento dos títulos inseridos nas Bibliotecas Digitais UC Digitalis, UC Pombalina e UC Impactum, pressupõem a aceitação plena e sem reservas dos Termos e Condições de Uso destas Bibliotecas Digitais, disponíveis em https://digitalis.uc.pt/pt-pt/termos.

Conforme exposto nos referidos Termos e Condições de Uso, o descarregamento de títulos de acesso restrito requer uma licença válida de autorização devendo o utilizador aceder ao(s) documento(s) a partir de um endereço de IP da instituição detentora da supramencionada licença.

Ao utilizador é apenas permitido o descarregamento para uso pessoal, pelo que o emprego do(s) título(s) descarregado(s) para outro fim, designadamente comercial, carece de autorização do respetivo autor ou editor da obra.

Na medida em que todas as obras da UC Digitalis se encontram protegidas pelo Código do Direito de Autor e Direitos Conexos e demais legislação aplicável, toda a cópia, parcial ou total, deste documento, nos casos em que é legalmente admitida, deverá conter ou fazer-se acompanhar por este aviso.

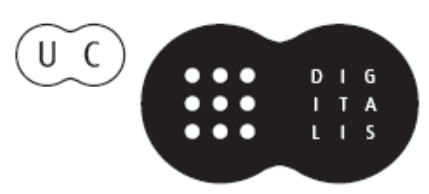




\section{Pólis/Cosmópolis}

\section{Identidades Globais \& Locais}

Carmen Soares, Maria do Céu Fialho \& Thomas Figueira (coords.)

IMPRENSA DA UNIVERSIDADE DE COIMBRA 


\title{
Regimes políticos nas HistóRIas de Heródoto. O “Diálogo dos Persas" (3. 80-82) \\ (Constitutions in Herodotus's Histories: The "Persian Dialogue" (3. 80-82))
}

\author{
CArmen Soares (cilsoares@gmail.com) \\ Universidade de Coimbra
}

Resumo - O propósito deste estudo é demonstrar que os capítulos 80-82 do livro III das Histórias de Heródoto apresentam não o retrato de três regimes e respectivos governates, o tradicional tríptico monarquia-oligarquia-democracia, mas permitem a subdivisão destas formas arquetípicas de governação em seis: três em que reina a excelência e outras tantas degeneradas.

Palavras-chave: Heródoto, teorização política, tirania, monarquia, democracia, oligarquia, regimes políticos de excelência, regimes políticos degenerados.

Aвstract - The main goal of this analysis of Hdt 3. 80-82 is to demonstrate that the historian does not propose a political theory based on three different constitutions: monarchy, oligarchy, and democracy. On the contrary, it is clear that by applying the qualifiers aristos and kakos to these forms of government, he offers a more complex arrangement of six constitutional archetypes, subdivided into triads of good and degenerate examples.

Keywords: Herodotus, political theory, tyranny, monarchy, democracy, oligarchy, "good" constitutions, "degenerate" constitutions.

A pertinência da reflexão sobre o tema da "teorização política" decorre, antes de tudo o mais, da necessidade de procurar e na possibilidade de encontrar, para o assunto em apreço, em textos da época (e estou a reportar-me ao séc. $V$ a. C), a fundamentação epistemológica caracterizadora do trabalho científico. Isto é, o estudo da praxis política é inseparável da reflexão sobre os princípios teóricos ou doutrinais que a enformam. Confirmando, neste domínio como em muitos outros, merecer o reconhecimento por parte dos estudiosos contemporâneos de ser voz fundadora da investigação histórica, Heródoto apresenta na sua obra uma análise pragmático-filosófica da politeia.

Nas Histórias vão sendo sucessivamente retratados monarcas bárbaros e tiranos gregos. Assim, quando, no livro III (caps. 80-82)ํㅜ , o leitor-ouvinte depara com o famosíssimo "Diálogo dos Persas" a sensação que tem é de que Heródoto, também em matéria de reflexão política, tem o cuidado de produzir um discurso científico, em conferir credibilidade ao seu logos (termo aqui aplicado no duplo

\footnotetext{
${ }^{1}$ Bibliografia principal sobre o episódio: Romilly 1959, Lasserre 1976, Evans 1981, Lateiner 1984, Rocha Pereira 1981 e 1990, Soares 2014.
} 
sentido de 'raciocínio, argumentação'). Ou seja, sente a urgência de produzir uma discussão dos fundamentos dos regimes de que apresentou (e continuará a apresentar) realizações concretas. A este propósito, devo desde já esclarecer que, para mim, a questão (insolúvel) da historicidade do diálogo assume uma importância marginal, quando comparada com o seu significado logikos. Mais do que saber se um grupo de nobres persas, em 522/1 a. C., discutiu realmente entre si a possibilidade de o reino passar de uma monarquia a uma oligarquia ou democracia, ou se Heródoto apenas está a colocar na boca de Bárbaros os argumentos que contemporanamente animavam as discussões pelo menos de algumas elites gregas, importa entender o episódio como a confirmação da racionalidade herodotiana ${ }^{2}$.

Isto é, o que verificamos é que o historiador não se limita a apresentar, de forma detalhada e em extensão diversa, retratos de monarcas orientais e tiranos gregos, cuja leitura nos permite tirar ilações sobre a caracterização dos respectivos regimes. Não! Ele próprio tem o cuidado (científico) de sustentar teoricamente essa pragmática política. Podemos, então, defender que os caps. 80-82 do livro III fornecem ao público uma "ficha de leitura" dos casos de governantes e governos já retratados e dos que as Histórias ainda lhe reservam.

É costume dizer-se, entre os comentadores do "Diálogo dos Persas", que aí encontramos a mais antiga fonte grega sobre a concepção de três regimes políticos distinguidos com base no critério numérico, a saber: o governo de um só (monarquia), o governo de poucos (oligarquia) e o governo de muitos (democracia). Pessoalmente não me revejo nesta interpretação, que considero redutora e, como tal, defensável apenas a um nível de leitura imediata. Entendo que o texto permite individualizar um maior número de politeiai, perfazendo um total de seis regimes distintos. Se não identifico já os respectivos nomes de cada um deles é porque sigo o método de investigação platónico ${ }^{3}$ segundo o qual não se deve partir de um nome para conhecer uma realidade, uma vez que só podemos saber o nome certo a dar-lhe depois de a conhecermos.

Outra ideia generalizada, esta de validade incontestável, é a de que o móbil da discussão reside na busca da melhor forma de governo, noção particularmente enfatizada na fala do último dos intervenientes no diálogo, Dario. Deste passo cito um pequeno excerto, no qual se encontra a chave para entendermos o princípio da aceitação de dois grupos distintos de regimes: os "melhores" (a que vem aplicado no texto o adjectivo aristos) e os "piores" (assim designados por mim, com base na caracterização negativa de que são alvo, como passarei a esclarecer).

\footnotetext{
${ }^{2}$ Sobre a historicidade ou não do diálogo, leia-se Pelling 2002 ('History').

${ }^{3}$ Cf. O Político 261 e (trad. Soares 2008).
} 
Dos três regimes que temos à nossa disposição, afirmo que - apesar de todos eles serem os melhores (é o melhor o governo do povo, a oligarquia e a monarquia) - este último é de longe superior aos outros. De facto nada se revela melhor do que um só homem dotado de excelência! (3. 82.1-2)

$\mathrm{Na}$ verdade, o futuro monarca persa nomeia apenas três formas de constituição. O que nos ajuda a compreender a tendência dos estudiosos para, seguindo de perto esta afirmação, proporem que Heródoto identifica apenas três politeiai ${ }^{4}$. Mas atentemos na contextualização das palavras de Dario. À testa da sua intervenção o que ele declara é que existem três formas exemplares de governar. No entanto, nas anteriores falas de Otanes e Megabizo, bem como no decurso desta, admitem-se tipos de governação que não se exercem sob o signo da excelência. Só num dos casos, no entanto, essa distinção entre a forma perfeita e a degenerada -chamemos-lhe assim - está na origem de nomenclatura distinta. Refiro-me, respectivamente, aos termos 'monarquia' e 'tirania'.

Assim, em vez de três politeiai, temos já quatro. Além disso, não é porque não se atribuem designações autónomas às formas piores do governo das massas e da oligarquia que devemos pensar que Heródoto não admita a individualização de mais duas formas de governo. Aliás, que essa poderia ser uma prática comum pelo menos às elites pensantes mais ou menos contemporâneas, é uma tese que colhe apoio em Platão. Quando, n' O Politico, o filósofo procede à divisão em dois do governo de um só, do governo de poucos e do governo do povo, no caso do último afirma:

No respeitante à democracia, quer as massas exerçam o poder sobre os detentores da riqueza pela força ou livremente, quer respeitem escrupulosamente ou não as leis, não há, em absoluto, o hábito de lhe mudar o nome.(292 a)

O que verdadeiramente permite distinguir os regimes não são, pois, os nomes que lhes damos, mas a ética dos seus governantes e alguns mecanismos de governação, como passarei de seguida a analisar.

Comecemos pelo 'governo de um só', ao qual Heródoto reserva papel de destaque, conforme se depreende até pelo facto de abrir e fechar o episódio com considerações sobre ele. Embora Otanes e Dario usem os mesmos nomes para falar dessa politeia e respectivo governante (mounarchie, mounarchos), pois são aqueles que literalmente significam 'governo de um só' e 'governante único', estão a reportar-se a realidades distintas.

\footnotetext{
${ }^{4}$ Repare-se que o autor nunca aplica este substantivo, mas sim pragmata (ou no singular pragma), com o sentido de 'feitos, negócios' (públicos, por oposição a privados), a saber 'governação'. Sobre esta interpretação, vd. Cartledge 2009: 4.
} 
O primeiro emprega a palavra monarquia ao exercício despótico do poder, da responsabilidade de um tirano, termo entendido no sentido pejorativo que ainda hoje lhe damos. Para que não haja dúvidas de que é esse o entendimento em causa, basta lembrar que o próprio Otanes usa como sinónimo do seu mounarchos a expressão 'homem tirânico' (aner mounarchos: 3. 80. 4). Concepção de que partilha Megabizo, que emprega não só o título tyrannos ao governante único (3. 81. 1), mas denomina de tyrannis o regime em que ele governa (3. 81. 2) $)^{5}$. Mais importante que os nomes, já o referi, é a caracterização dos regimes e respectivos governantes. Atentemos, então, neste aspecto.

Sobre a politeia de um só stricto sensu, apresentada por Otanes, retiramos um retrato do que ela não é: nem 'agradável' (hedy), nem 'boa' (agathon). Fica, assim,

${ }^{5}$ Em suma, o termo monarchos tem o sentido neutro de 'governante (único)', donde a sua utilização como sinónimo de tyrannos. Este, por sua vez, implica, no Diálogo dos Persas, o sentido de 'governante (único) despótico'. Este assunto foi já tratado de forma bem documentada por Ferril 1978. No entanto, ao contrário de Rosivach 1988, não considero que, pelo menos no que toca a Heródoto, possamos defender que tyrannos e monarchos, assim como tyrannis e monarchia, sejam apenas sinónimos. O que a análise do texto herodotiano atesta, como passarei a demonstrar, é que o desenho do retrato do tirano se faz por antítese com o do bom monarca (tratamento que, diversamente do que defende o estudioso na p. 56, não é apenas característico de Xenofonte e Aristóteles). Um outro estudo a ter em conta sobre o sentido do termo tyrannos é o de Parker 1988. Não obstante a validade do levantamento e estudo analítico das ocorrências do termo, as conclusões retiradas merecem-me algumas reservas, sobretudo quanto à interpretação apresentada para o texto das Histórias. Mas, mesmo fora do testemunho do autor agora em apreço, é possível encontrar contradicções no seio da argumentação de Parker. Refiram-se algumas das mais evidentes: a tese de que tyrannos se distingue de basileus porque este designa "a good or legitimate absolute monarch" e aquele "an in some way wicked or illegitimate absolute monarch" (p. 145) não se coaduna com a observação que faz a propósito da leitura da Política de Aristóteles, quando afirma que o Estagirita, ao denominar de 'tiranos' indivíduos que herdaram o poder, "simply neglects the hereditary characyer of tiranny" (p. 167). Ou seja, a legitimidade de um tirano subir ao poder baseia-se, pelo menos em parte, num critério que assiste também ao rei (a hereditariedade), logo tirania e realeza não se distinguem com base no argumento da legitimação do poder, porque nem sempre o tirano sobe ao poder ilegalmente. Particularmente forçada parece-me a argumentação de que só no dialecto ático há uma distinção clara entre tyrannos e basileus e que nos restantes contextos linguísticos funcionavam como sinónimos. Para não me alongar demasiado nesta questão, bastará lembrar que o próprio Parker abona a sua tese com testemunhos que a contradizem. Por um lado afirma (p. 169) que a comédia ática tanto usa o termo com o sentido positivo que se encontra na lírica, como com o valor de poder tomado pela força (logo ilegal). Tal não devia suceder se a distinção entre bom governo (monarquia) e mau governo (tirania) fosse uma marca linguística! Dizer que Heródoto, porque escreveu em iónico, não fez distinção entre tiranos e reis (p. 171), causa igual perplexidade. A verdade é que no seu texto, em particular no que agora estamos a analisar, essa distinção de valores é bem nítida. Se o historiador em determinados passos emprega tyrannos com sentido neutro (i. e., sinónima de basileus e monarchos) tal facto decorre, quanto a mim, da simples razão de ao seu tempo essa ser uma prática linguística corrente, que não é imcompatível com a clara consciência, já existente (e que não será, por conseguinte, uma inovação tucididiana, como defende o comentador, cf. pp. 170 sq.), entre monarquia, entendida como boa forma de governação de um só, e tirania, a realização negativa do exercício monocrático. 
automaticamente excluída do grupo das melhores formas de governação. Como procedimentos emblemáticos do sistema identifica a ausência de mecanismos de controlo das finanças públicas e da actuação do governante. Ou seja, como diz o Persa, aquele não tem que prestar contas e faz o que lhe apetece (3. 80. 3). Se ao governante único é conferida, como estamos a ver, uma liberdade total de movimentos, é evidente que se está a transferir a responsabilidade da boa ou má governação para o seu carácter. Esta ingerência determinante da moral na política constitui no texto herodotiano, como terei o cuidado de sublinhar várias vezes no decurso desta reflexão, um elemento comum ao perfil de todas as politeiai.

O que nos diz Otanes sobre a alma do monarca tirano? Para responder a esta interrogação, terei que começar por apresentar duas ideias que, sendo prévias, no texto, a essa caracterização, são de todo indispensáveis ao seu cabal entendimento: o poder absoluto corrompe a alma, mesmo a de um indivíduo que mereça a distinção de ser tido na conta de 'o melhor de todos os homens' (ton ariston andron panton, ibidem); a alma humana possui um defeito inato, a inveja (phthonos, ibidem). Se adicionarmos a esta propensão natural para o vício da inveja uma vida próspera, estão reunidas as condições que explicam o aparecimento da 'insolência' (hybris), a segunda das características que autorizam Otanes a denominar de 'absoluta vilania' (pasa kakotes) e de 'todo o tipo de destemperos' (polla kai atasthala) a actuação do tirano.

A propósito da noção de que é a abundância de bens que estimula a faceta invejosa do tirano a cometer abusos de poder, a personagem tem o cuidado de sugerir que essa é uma das incompreensões (diríamos nós) da psicologia do governante único. A inveja, apesar de inata, deixa de ser moralmente justificável quando o sujeito vive desafogadamente, pelo que, ao contrário do que sucede, o tirano devesse ser 'não-invejoso' (aphthonos: 3. 80. 4). A segunda das perplexidades ético-comportamentais suscitadas pelo retrato do tirano consiste no que entendo designar por baixo nível de auto-estima. A falta de confiança no mérito pessoal e na aceitação social das suas acções levam o tirano a hostilizar os seus pares ou indivíduos moralmente superiores (ideias contidas no uso do adjectivo aristos, cf. ibidem) e a rodear-se de cidadãos de baixa extracção, social e/ou ética (os kakistoi, cf. ibidem). Uns - é fácil deduzi-lo - representam a ameaça de potenciais rivais; outros afiguram-se uma base de apoio manipulável e obediente. A mesma insegurança explica o entusiasmo com que o tirano acolhe as calúnias e a insatisfação permanente que nele causam os elogios de terceiros, ora tidos por desconsideração (quando moderados), ora encarados como actos de bajulação (quando mais profusos) (3. 80.5).

Em jeito de corolário do retrato do monarca tirânico, Otanes enuncia três comportamentos por si qualificados de 'os mais graves' (ta megista, ibidem): alterar os costumes pátrios, exercer violência sobre as mulheres e condenar à morte sem julgamento. Ao ser apresentada nestes termos, a tirania, produto da 
actuação do tirano, significa o ruir de alicerces fundamentais da pólis grega: as normas, a moderação e a justiça.

Bem diversa deste governo despótico de um só é a monarquia retratada por Dario. O primeiro contraste evidente encontramo-la na relação entre ethos e política. Enquanto Otanes admite que o exercício do poder influencia o carácter do governante, corrompendo-o, Dario tem uma posição absolutamente contrária. Conforme vimos supra (a propósito da citação de 3. 82. 2), a preferência pela melhor forma de monarquia fá-la com base na ética. É porque a governa 'um único homem dotado de excelência' que o regime de um só é o preferido de Dario. $\mathrm{O}$ carácter do governante é que lhe confere a competência para ser o 'intendente' das massas.

O regime, mesmo quando governado por um monarca perfeito, continua, no entanto, a estar sujeito à ruína, como se depreende da condição identificada por Dario para que se mantenham as suas virtudes. O requisito em questão é, uma vez mais, de natureza moral, a saber: o monarca não pode revelar as suas decisões a 'indivíduos mal formados' (dysmeneas andras, 3. 82. 2). Ou seja, na monarquia os perigos de degeneração do regime não derivam do carácter do governante, como sucedia na tirania, mas da imoralidade de terceiros.

Esta ideia de que as formas de constituição podem degenerar constitui, aliás, um motivo central para percebermos a razão de Dario fazer a apologia da monarquia como o melhor dos melhores pragmata. Como vimos, a degeneração da monarquia, a acontecer, nunca derivará do governante, mas dos governados. Já no que se refere à oligarquia e ao governo do povo, são os próprios governantes os responsáveis pela sua ruína (manifestada em perturbações sociais sangrentas, próprias da stasis). Ou seja, porque a monarquia é, na essência (i.e., no que concerna o governante), sempre 'o melhor' (to ariston), cabe-lhe o papel de "constituição regeneradora". Como esclarece o texto, quando o regime de poucos e o da multidão colapsam, a monarquia é sempre a resposta para a salvação da polis. E este é o argumento político mais claro da primazia conferida pelo nobre persa à monarquia.

As duas formas de governo de um só, monarquia e tirania, são aquelas que mais extensamente vêm caracterizadas no texto. Esse relevo reflecte, quanto a mim, as posições extremas que parecem ocupar no quadro da teorização política herodotiana. A primeira, acabámos de ver, afigura-se a melhor das melhores (3. 82. 2), a segunda colhe, da parte dos dois intervenientes que a consideram, apenas críticas violentas. Por ser esta a única politeia a não merecer qualquer caracterização positiva, julgo legítimo propor para ela o título de "pior regime" de todos. Falta-nos considerar as formas de governo oligárquico e democrático, ambas alvo tanto de elogios como de críticas.

Embora conhecesse e usasse o nome demokratie (cf. 6. 43.3 e 131. 1) e o verbo demokrateomai (cf. 4.137. 2, 6. 43. 3), Heródoto não aplica nenhum deles no único passo da sua obra em que faz a discussão teórica das diferentes politeiai. 
Prefere falar de 'governo/poder (arche/kratos) das massas/povo (plethos/demos)', sinónimos de isonomie (3. 80. 6). Podemos ler, nestas escolhas de terminologia, um indicador de que, à volta do último quartel do séc. $V$ a. C., i. e., volvido quase um século sobre o nascimento da democracia (se tivermos em conta o caso ateniense, que não foi o primeiro ${ }^{6}$ ), o regime é vulgarmente identificado através das suas duas características mais genuínas: ser um governo em que a maioria dos governantes (a 'multidão', como indica o termo grego plethos) é de origem social humilde (o demos); os governantes possuirem uma parte (nomos) igual (isos) no governo da polis.

A propósito da interpertação que estou a propor para isonomia ('ter uma parte igual de'), impõe-se esclarecer que é o texto herodotiano que sugere esta leitura abrangente. Ou seja, a declaração de Otanes de que o governo do povo tem o mais belo dos nomes: isonomia ${ }^{7}$ vem seguida da descrição detalhada do modus faciendi político que justifica a atribuição dessa titulatura. É porque os cidadãos acedem aos cargos por tiragem à sorte, porque são obrigados a prestar contas do uso de fundos públicos e porque tomam as decisões em comum, é graças a estas três formas de funcionamento que se pode falar de 'governação partilhada' ou, se preferirmos o termo grego, de isonomia ${ }^{8}$.

Não podemos, no entanto, descontextualizar a reflexão acabada de fazer. Assim, ao mesmo tempo que servem de emblemas do governo do povo, os mecanismos de gestão do poder enunciados desempenham, no âmbito da fala de Otanes, o papel de reversos positivos de defeitos concretos por ele apontados à tirania (poder discricionário e autocrático e impunidade de que goza o governante). Em suma, como sugere a atribuição do superlativo kalliston ao nome isonomia, estamos perante a versão perfeita da democracia ou, como escreve Heródoto na fala de Dario, perante 'o povo no seu melhor' (demou te aristou, 3. 82. 1).

Ao futuro rei da Pérsia e a Megabizo atribui o nosso Autor a descrição da versão negativa da democracia. Os dois apresentam-na como um 'mau' regime. O primeiro aplica-lhe o adjectivo neutro substantivado 'vil' (kakon: 3. 81. 3). O segundo reduz todas as suas acções a 'vilania' (kakotes), chama os governantes

${ }^{6}$ As instituições democráticas teriam surgido por volta de inícios ou meados do séc. VI a. C. em poleis como Mileto, Mégara, Samos e Quios (Ferreira 1990, A democracia: 11).

${ }^{7}$ Isonomia é a forma ática correspondente ao iónico que o texto apresenta: isonomie.

${ }^{8}$ Como facilmente se depreende, considero que Heródoto não usa o nome no sentido restrito de 'igualdade perante a lei'. Contudo, essa noção não fica excluída, se aceitarmos que se aplica a todas as decisões que o povo é levado a tomar no âmbito do governo das diversas instituições democráticas (grupo em que incluímos, além da Assembleia, o órgão deliberativo por excelência, os Tribunais do Povo). Também Rosivach (1988: 47-48 e nn. 11 e 14) defende esta interpretação etimológica, cuja validade vê confirmada na oposição que desde cedo (na canção de mesa de Harmódio e no frag. 4 Diels de Alcméon) se estabelece entre isonomia e poder de um só. 
'vilões' (kakoi) e denomina o modo de agir destes pelo verbo da mesma família semântica (kakeo: 3. 82. 4). Verificamos, uma vez mais, que o carácter dos governantes (i. e., a ética) molda o regime (i. e., a politeia).

Os governantes kakoi são pessoas que carecem de virtudes morais e de instrução, de acordo com a caracterização que Megabizo faz das massas. O defeito da insolência, também apontado ao tirano, é uma das duas maiores pechas da gestão popular (veja-se o uso da forma superlativa 'o mais insolente', hybristeteron: 3. 81. 1). O outro é a estupidez ('o mais estúpido', axynetoteron, novo uso de superlativo), que, mais do que o resultado de um QI baixo (hipótese sem apoio no texto), deve derivar da falta de educação. É o que sugere Megabizo ao afirmar que, ao contrário do tirano, que, quando comete actos de hybris, sabe o que está fazer, o povo não possui conhecimento, pois como se lê em 3. 81. 2:

Como poderia, pois, ter conhecimento quem não foi ensinado, não sabe o que é belo, nem sabe nada por si próprio e, sem pensar, se atira à governação, semelhante a um rio de torrentes invernosas?

$\mathrm{Na}$ verdade, o povo, por falta de recursos, não teria o mesmo acesso à formação que as elites (aristocráticas e/ou endinheiradas), paradigma de educação tradicionalmente referenciado pela expressão completa 'o belo e o bom'. Mais ainda: esse é um saber e uma formação moral que não se compadecem com autodidactismos - como acabámos de ouvir dizer a Megabizo. Convém lembrar que a denúncia da falta de competência (leia-se formação) do povo vem posta na boca de um legítimo porta-voz da classe privilegiado dos nobres. À falta de instrução parece também ligar-se a tomada de decisões irreflectidas, outra atitude censurável própria das massas.

Deixámos para o fim ponderar a atribuição do adjectivo 'incontrolável' (akolastos, 3. 81. 2) ao povo, uma vez que, ao implicar a noção de desordem, nos remete para o início da fala de Otanes. Aí, ao afirmar-se o que a monarquia tirânica não é, subentendem-se os princípios norteadores da boa governação. Esta deve buscar não só 'o que é agradável e belo' (3. 80. 2), como já referi, mas também 'a organização do estado' (chrema katertemenon, 3. 80. 3). Fica, deste modo, mais evidente que a governação democrática, concebida nos termos enunciados por Megabizo, não pode, de forma alguma, corresponder ao perfil da sua versão aristos, anteriormente desenhada por Otanes.

Mas voltemos à fala de Megabizo. Chegados a este ponto da análise, pensamos poder compreender melhor o porquê de chamar à 'multidão' uma 'mole incompetente' (bomilou gar achriou). Se a ignorância, a insolência, a indisciplina e a irreflexão são defeitos dos indivíduos da classe popular, a consequência natural desses defeitos só pode ser um 'corpo governativo' (homilos) 'sem qualquer utilidade' (a-chreios). Também os governantes do regime 
oligárquico vêm designados por um substantivo da família de homilos, que, como acabámos de notar, Megabizo aplica ao povo: homilia. Ou seja, o contraste imediato entre monarquia e tirania, por um lado, e democracia e oligarquia, pelo outro, consiste em que, nas primeiras, o exercício do poder é exclusivo de um governante, nas segundas é partilhado por uma 'assembleia' de indivíduos (homilos ou homilia).

Para Megabizo a diferença entre o homilos popular e a homilia nobre reside na formação ética dos seus membros, o que tem consequências políticas directas, pois, como podemos ler no texto, é natural as melhores decisões surgirem dos melhores homens (3. 81. 3).

$\mathrm{Na}$ fala de Dario encontramos um critério novo para avaliar a boa governação: o serviço público ou, como se diz em grego, o serviço prestado ao 'interesse comum' (to koinon). Além de insistir na distinção social e ética entre oligarcas (possuidores da arete) e povo (os kakoi), a personagem põe em evidência a política contrastante que as duas formas de governo têm naquela matéria. Ou seja (3. 82 . 3-4):

3. Na oligarquia é costume surgirem, entre o grande número de indivíduos que coloca o seu mérito ao serviço do interesse comum, poderosas rivalidades pessoais: de facto cada um deles, movido pelo desejo de liderar e de fazer vencer as suas propostas, leva a que apareçam, entre si e os outros, rivalidades insanáveis, das quais nascem dissensões, das dissensões homicídios e dos homicídios desemboca-se numa monarquia, e, com isto, torna-se evidente o quanto este é o melhor regime.

4. Quando o povo governa, é inevitável o aparecimento da vilania! E quando a vilania se orienta para o interesse comum, o que surge entre os vilões não são rivalidades, mas sim poderosas alianças! A verdade é que os que cometem actos de vilania contra o interesse comum se encobrem mutuamente.

Enquanto, no primeiro caso, a 'coisa pública' serve de palco à tradicional competição dos aristocratas pelo protagonismo (leia-se arete); no segundo estimula a união entre os mais humildes, pois só assim conseguem o mútuo encobrimento da responsabilidade de todos numa governação ruinosa.

Em conclusão, o "Diálogo dos Persas" revela a pluralidade de regimes conhecidos no séc. V. a. C. A partir de três politeiai nucleares - distinguidas com base no critério do número de governantes - as personagens herodotianas caracterizam seis regimes distintos: três "perfeitos" (ou, como se diz em grego, aristoi) e três "degenerados" (que no texto vêm associados à ideia de kakotes). Embora tenhamos de aguardar por Platão para encontrar uma reflexão teórica mais apurada desta distinção, a verdade é que as Histórias permitem individualizar claramente: monarquia, tirania, oligarquia "melhor", oligarquia "pior", democracia "melhor" e democracia "pior". 
Este é o espectro conceptual que Heródoto conhece e apresenta. Apenas isso! Considero, portanto, despropositado questionar se se pode identificar alguma das posições dos três intervenientes no diálogo como sendo a do Autor. No domínio da teorização política, como noutros, o historiador mantém-se imparcial, pelo que, neste passo, apresenta todos os modelos de governação e respectivos governantes sem deixar transparecer qualquer juízo pessoal sobre a matéria. 


\section{Bibliografia Final}

AA.VV. (1990), Archéologie de la vigne et du vin. Actes du colloque 28-29 mai 1988, Paris.

AA.VV. (1992), Archeologia del paesaggio. IV Ciclo di lezioni sulla ricerca applicata in archeologia, Certosa di Pontignano (Siena) 14 - 26 gennaio 1991, Firenze.

AA.VV. (1997), Uomo, acqua e paesaggio. Atti dell'incontro di studio sul tema irreggimentazione delle acque e trasformazione del paesaggio antico, S. Maria Capua Vetere 22 - 23 novembre 1996, Roma.

AA.VV. (1998), El vi a l'antiguitat. Economia, producció i comerç al Mediterrani occidental. II Colloqui internacional d'arqueologia romana. Actes. Badalona, 6 - 9 de maig de 1998, Badalona.

AA.VV. (1999), El vino en la antigüedad romana. Simposio arqueología del vino, Jérez 2, 3 y 4 de octubre 1996, Madrid.

AA.VV. (1999b), Environmental reconstruction in Mediterranean landscape archaeology, Oxford.

AA.VV. (2001), La cerveza en la antigüedad, Sevilla.

AA.VV. (2004), Le vin. Nectar des dieux, génie des hommes, Gollion.

Abascal, J. Manuel, Espinosa, Urbano (1989), La ciudad hispano-romana. Privilegio y poder, Logronho.

Abásolo, J. A., Mayer, M. (1997), "Inscripciones latinas”, in S. Corchón (coord.), La Cueva de la Griega de Pedraza (Segovia), Zamora, 183-259.

Abbondanza, L. (ed.) (2008), Filostrato Maggiore, Milano.

Acosta-Hughes, B. (2002), Polyeideia. The Iambi of Callimachus and the Archaic Iambic Tradition, Berkeley and Los Angeles.

Adams, C. (2001), "There and back again. Getting around in Roman Egypt", in Adams, C. and R. Laurence (eds.), Travel and Geography in the Roman Empire, Londres and Nova Iorque, 138-166.

Adams, J. N. (2003), Bilingualism and the Latin language, Cambridge.

Adams, J. N. (2003a), “Romanitas and the Latin language”, CQ 53: 184-205.

Affatato, R. (2010), "Nueva York: recepción del mito de la ciudad en Federico García Lorca e Italo Calvino", in J. M. Losada Goya (ed.), Mito y mundo contemporáneo. La recepción de los mitos antiguos, medievales y modernos en la literatura contemporánea, Bari, 627-640.

Albuquerque, M. de (1968), O poder politico no Renascimento português, Lisboa.

Albuquerque, M. de (1981), "Bártolo e bartolismo na história do direito português”, Boletim do Ministério da Justiça 304: 41-61.

Albuquerque, M. de (1983), Estudos de cultura portuguesa, I, Lisboa. 
Alexandrescu-Vianu, M. (1988), “O nouă posibilă genealogie a familiei lui Hippolochos, fiul lui Theodotod, de la Histria”, SCIVA 39.3: 275-280.

Alexandrescu-Vianu, M. (1989), "Apollon Ietros. Ein verschollener Gott Ioniens?”, IstMitt 39: 115-122.

Alexandrescu-Vianu, M. (1990), "Die Steinskulptur von Histria", in P. Alexandrescu, W. Schuller (eds.) Histria. Eine Griechenstadt an der rumänischen Schwarzmeerkünste, Xenia. Konstanzer Althistorische Vorträge und Forschungen 25, Konstanz, 179-232.

Alexandrescu-Vianu, M. (2000), "Une alternative d'identification de la statue colossale d'Istros", in A. Avram, M. Babeş (eds.) Civilsation grecque et cultures antiques périphériques. Hommages à $P$. Alexandrescu à son $70^{\circ}$ anniversaire, Bucarest, 274-281.

Alexandridis, A. (2004), Die Frauen des römischen Kaiserhauses. Eine Untersuchung ibrer bildlichen Darstellung von Livia bis Iulia Domna, Mainz.

Alfayé, S., Marco, F. (2008), "Religion, language and identity in Hispania: Celtiberian and Lusitanian rock inscriptions", in R. Häußler (ed.), Romanisation et épigraphie. Etudes interdisciplinaires sur lacculturation et lidentité dans l,Empire romain, Montagne.

Alföldi, A. (1948), The conversion of Constantine and Pagan Rome, Oxford.

Alföldy, G. (1969), Fasti Hispanienses, Wiesbaden.

Alföldy, G. (1973), Flamines provinciae Hispaniae citerioris, Madrid.

Alföldy, G. (1991), "Augustus und die Inschriften: Tradition und Innovation. Die Geburt der imperialen Epigraphik”, Gymnasium 98: 289-324.

Allen, A. (1951), History of political thought in the sixteenth century. London

Altaner, B., Stuiber, A. (2a ed. 1972), Patrologia, São Paulo.

Amouretti, M.C., Brun J.-P. (eds.) (1993), La production du vin et de l'buile en Méditerranée. Actes du symposium international organisé par le Centre Camille Jullian et le Centre archéologique du Var, Aix-en-Provence et Toulon 20-22 novembre 1991 (BCH suppl. 26), Athènes.

Ando, C. (2003), "A Religion for the Empire", in A. J. Boyle, W. J. Dominik (eds.), Flavian Rome. Culture, Image, Text, Leiden, Boston 323-344.

Ando, C. (2006), "Interpretatio Romana”, in L. de Blois, P. Funke, J. Hahn, (eds.), The Impact of Imperial Rome on Religions, Ritual and Religious Life in the Roman Empire, Proceedings of the Fifth Workshop of the International Network Impact of Empire (Roman Empire 200 B.C. - A.D. 476.), Leiden, Boston 51-65.

Andrade, A. A. (1959), S. Tomás de Aquino no periodo áureo da filosofia portuguesa, Lisboa.

Andrade, A. A. de (1965), Antologia do pensamento politico português (séc. XVI), vol. I. Lisboa. 
Andrade, M. (1974), "Lira Paulistana”, in Poesias completas, São Paulo.

Andreu, J. (2004), Edictum, Municipium y Lex: Hispania en época flavia (69-96 d. C.), BAR Int. Ser. 1293, Oxford.

Antonietti, C. (1999), "Megara e le sue colonie: unità storico-culturale?”, in C. Antonetti, P. Lévêque (eds.) Il dinamismo della colonizzazione greca, Atti della tavola rotonda "Espansione e colonizzazione greca di età arcaica: metodologie e problemi a confront", Venezia, 10-11/11, Besançon-Paris, 17-24.

Aquino, T. de (1946), Des lois de Saint Thomas d'Aquin. Texte traduit et présenté par J. de la Croix Kaelin O. P., Paris.

Arnaldi, A. (2010), “Osservazioni sul flaminato dei Divi nelle provincie africane”, in M. Milanese, P. Ruggeri, C. Vismara, (eds.), L'Africa romana. Luoghi e le forme dei mestieri e della produzione nelle provincie africane. Atti del XVIII convegno di studio. Olbia 11-14 dicembre 2008, vol. III, Roma, 1645-1665.

Arruda, A. M. (2005), "O 10 milénio a.n.e. no Centro e no Sul de Portugal: leituras possíveis no início de um novo século", O Arqueólogo Português Série IV: 23: 59-74.

Arzone, A. (2011), “Alcune considerazioni sulle immagini di pietre miliari e sui riferimenti alle strade nel documento monetale", in I miliari lungo le strade dell'Impero. Caselle di Somma campagna Verona, 77-92.

Asensi, R. M., Musso, O. (1990), "Un documento etrusco di Tarragona", Quaderni della sezione di Studi Storici Alberto Boscolo 1: 5-11.

Aston, M. (1997), Interpreting the landscape. Landscape archaeology and local bistory, London.

$A T L=$ B.D. Meritt, WadeGery, H.T., McGregor, M.F., The Athenian Tribute Lists, 4 vs, Princeton.

Aubert, J.-M. (1955), Le droit romain dans l'oeuvre de Saint Thomas, Paris.

Avery, H. C. (1971), "Euripides' Heraclidae", AJPh 92: 539-565.

Avram, A., Lefèvre, F. (1995), "Les cultes de Callatis et l'oracle de Delphes", REG 108: 7-23.

Bacchielli, L. (1986), "Monumenti funerari a forma di cupula: origine e diffusione in Italia meridionale", in A. Mastino (ed.), L' Africa Romana: atti del 3. convegno di studio Sassari 13-15 dicembre 1985, Sassari, 303-319.

Bailly, A. (1963), Dictionnaire grec-français, Paris.

Balass, G. (s.d.), "The Female Breast as a Source of Charity: Artistic Depictions of Caritas Romana", www.Academia.edu/4006836.

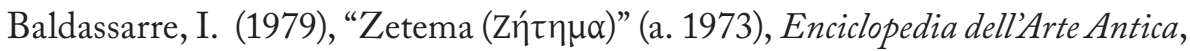
Suppl. 1979: 944-945.

Baldassarre, I., Bragantini, I., Morselli, C. and Taglietti, F. (1996), Necropoli di Porto. Isola Sacra, Roma. 
Balil, A. (1984-88), "Las cupae de Barcino. Contribución al estudio de un tipo de monumento funerario romano", Arqueologia e Historia: 111-115.

Baratta, G. (1993), “Una divinità gallo-romana. Sucellus. Un’ipotesi interpretativa”, ArchCl 45: 233-247.

Baratta, G. (1994), "Circa Alpes ligneis vasis condunt circulisque cingunt", ArchClass 46: 232-260.

Baratta, G. (1997), "Le botti: dati e questioni”, in Techniques et économie antique et médiévale. Le temps de l'innovation. Colloque international, Aix-enProvence 21-23 Mai 1997, Paris, 109-112.

Baratta, G. (1997), "Sucellus", in Enciclopedia dell'Arte Antica classica e orientale, Supplemento 1991-1994, V, Roma, 482.

Baratta, G. (2005a), "La cupa nell'ambito femminile: dalla caupona al loculus?”, in, F. Cenerini, A. Buonopane (eds.), Donna e vita cittadina nella documentazione epigrafica, 95-108.

Baratta, G. (2005b), Römische Kelteranlagen auf der italienischen Halbinsel. Ein Überblick über die schriftlichen, bildlichen und archäologischen Quellen (200 v.Chr. - 400. n.Chr.) (Cornucopia, 11), Murcia.

Baratta, G. (2005c), “Appunti sulle variabili e costanti dell' interpretatio religiosa nell'occidente romano, in F. de Oliveira, (ed.), Génese e consolidação da Ideia de Europa, vol.III, O Mundo Romano, Coimbra, 123-134

Baratta, G. (2006a), "Alcune osservazioni sulla genesi e la diffusione delle cupae", in Atti del XVI Convegno internazionale de L'Africa Romana (Rabat, 15-19 dicembre 2004), Roma, 355-368.

Baratta, G. (2006b), "Nuovi dati sull'iconografia delle mandorle nei sarcofagi strigilati. Un primo approccio ad un corpus", Annali della Facoltà di Lettere e Filosofia dell'Università di Macerata 26: 65-120.

Baratta, G. (2007), "La mandorla centrale dei sarcofagi strigilati. Un campo iconografico ed i suoi simboli", in F. Hoelscher, T. Hoelscher (eds.), Römische Bilderwelten. Von der Wirklichkeit zum Bild und zurück. Kolloquium der Gerda Henkel Stiftung am Deutschen Archäologischen Institut Rom, Heidelberg, 191-215.

Baron, H. (1938), "Cicero and the Roman civic spirit in the Middle Ages and the Early Renaissance", Bulletin of the John Rylands Library 22: 84-89.

Baron, H. (1970), La crisi del primo Rinascimento italiano, Firenze.

Barresi, P. (2007), "Il sofista Flavio Damiano di Efeso e la costruzione di termeginnasi nell'Asia Minore romana di età imperiale", in O. D. Cordovana, M. Galli, (eds.), Arte e memoria culturale nell'età della Seconda Sofistica, Catania, 137-151.

Barros, J. de (1919), Geografia d'Entre Douro e Minho e Trás-os-Montes, Porto. 
Barros, J. de (1937), Panegíricos - Panegírico de D. João III e da Infanta D. Maria, Texto restituído, prefácio e notas por M. Rodrigues Lapa, Lisboa.

Bassignano, M.S. (1974), I faminato nelle provincie romane dell'Africa, Roma.

Bastos, E. (1991), Entre o escândalo e o sucesso. A semana de 22 e o Armory show, Campinas.

Battaglia, M. (2003), "Il Vulcano dei Germani in Giulio Cesare (B.G. VI, 21, 1). Un caso di interpretatio?", Athenaeum 91: 373-401.

Beagon, M. (2005), The Elder Pliny on the Human Animal: Natural History Book 7, Oxford.

Beard, M., North, J., Price, S. (1998), Religions of Rome, vol. I, A History, Cambridge.

Behr, C.A. (ed.) (1973), Aristides, vol. I, Panathenaic Oration in Defence of Oratory, London.

Behrends, M. et alii (eds.) (2000), Hygin. L'oeuvre gromatique, Luxemburg.

Bejarano Osorio, A. M. (1996), "Sepulturas de incineración en la necrópolis oriental de Mérida: las variantes de cupae monolíticas", Anas 9: 37-58.

Belmonte, J. A. (2010), "Documentación fenicio-púnica en la Península Ibérica: estado de la cuestión", in G. Carrasco y J. C. Oliva (eds.), El Mediterráneo antiguo: lenguas y escrituras, Cuenca, 159-220.

Beltrán, F. ed. (1995), Roma y el nacimiento de la cultura epigráfica en occidente, Zaragoza.

Beltrán, F. (2000), "La vida en la frontera", in F. Beltrán, M. Martín-Bueno y F. Pina, Roma en la Cuenca Media del Ebro. La romanización en Aragón, Zaragoza.

Beltrán, F. (2002), "Identidad cívica y adhesión al príncipe en las emisiones municipales hispanas", in F. Marco, F. Pina y J. Remesal (eds.), Religión y propaganda politica en el mundo romano, Barcelona, 159-187.

Beltrán, F. (2004), "E1 latín en la Hispania romana: una perspectiva histórica", in R. Cano (ed.), Historia de la lengua española, Barcelona, 83-106.

Beltrán, F. (2004a), "Nos Celtis genitos et ex Hiberis. Apuntes sobre las identidades colectivas en Celtiberia", in G. Cruz Andreotti y B. Mora Serrano (eds.), Identidades étnicas - Identidades políticas en el mundo prerromano hispano, Kronion 1, Málaga, 87-145.

Beltrán, F. (2004b), “De nuevo sobre la tésera Froehner", Palaeohispanica 4: 4565.

Beltrán, F. (2004c), "Imagen y escritura en la moneda hispánica", in F. Chaves y F. J. García (eds.), Moneta qua scripta. La moneda como soporte de la escritura. Actas del III Encuentro Peninsular de Numismática Antigua, Anejos de AEspA 33: 125-139. 
Beltrán, F. (2004d), "Libertos y cultura epigráfica en la Hispania republicana", in F. Marco, F. Pina y J. Remesal (eds.), Vivir en tierra extraña: emigración e integración cultural en el mundo antiguo, Barcelona, 151-175.

Beltrán, F. (2005), "Cultura escrita, epigrafía y ciudad en el ámbito paleohispánico", Palaeohispanica 5: 21-56.

Beltrán, F. (2006), "Hispania y el Mediterráneo en los siglos II y I a. E.: diversidad cultural y movilidad social", in F. de Oliveira, P. Thiercy, R. Vilaça (eds.), O mar greco-latino, Coimbra, 223-240.

Beltrán, F. (2009), "Vltra eos palos. Una nueva lectura de la línea 7 de la Tabula Contrebiensis", in Espacios, usos y formas de la epigrafía hispana en épocas antigua y tardoantigua. Homenaje al Dr. Armin U. Stylow, Anejos de AEspA 48: 33-42.

Beltrán, F. (2011), "Lengua e identidad en la Hispania romana”, Palaeohispanica 11:19-59.

Beltrán, F. (2011a), “Firmas de artesano o sedes de asociaciones comerciales? A propósito de los epígrafes musivos de Caminreal (E.7.1), Andelo (K.28.1) y E1 Burgo de Ebro (HEp 11, 2001, 621 = AE 2001, 1237)", in E. Luján y J. M. García Alonso (eds.), A Greek man in the Iberian street. Papers in Linguistics and Epigraphy in honour of Javier de Hoz. Innsbrucker Beiträge zur Sprachwissenschaft 140, Innsbruck, 139-147.

Beltrán, F. (2011b), “Les colonies latines d'Hispanie (IIe siècle av. E.): émigration italique et intégration politique", in N. Barrandon y F. Kirbihler (eds.), Les gouverneurs et les provinciaux sous la République romaine, Rennes, 131-144.

Beltrán, F. (2012), "Roma y la epigrafía ibérica sobre piedra del nordeste peninsular", Palaeohispanica 12: 9-30.

Beltrán, F. (inédito), "Diversidad cultural y epigrafía: el ejemplo de Hispania", XII Congressus Internationalis epigraphiae Graecae et Latinae, Barcelona septiembre de 2002.

Beltrán, F., Estarán, M. J. (2011), “Comunicación epigráfica e inscripciones bilingües en la Península Ibérica”, in C. Ruiz Darasse y E. Luján (eds.), Contacts lingüistiques dans l'Occident méditerranéen antique. Collection de la Casa de Velázquez (126), Madrid, 9-25.

Beltrán, F., Velaza, J. (2009), "De etnias y monedas: las "cecas vasconas", una revisión crítica", in J. Andreu (ed.), Los vascones de las fuentes antiguas: en torno a una etnia de la antigüedad peninsular, Barcelona, 99-126.

Beltrán, F., Arasa, F. (1979-1980), "Los itineraria privata en la epigrafía latina”, Historia Antiqua, 9-10: 7-29.

Beltrán, F., Jordán, C., Marco, F. (2005), "Novedades epigráficas en Peñalba de Villastar (Teruel)", Palaeohispanica 5: 911-956.

Bentley, J. H. (1978), Politics and culture in Renaissance Naples, Princeton. 
Berciu, I.,Wolski, W. (1970), "Un nouveau type de tombe mise au jour à Apulum et le problème des sarcophages à voûte de l'Empire romain”, Latomus 29: 919-965.

Bergmann, M. (1998), Die Strablen der Herrscher. Theomorphes und politische Symbolik im Hellenismus und in der römischen Kaiserzeit, Mainz.

Berruti, V., Magistà, A. (eds.) (2009), L'automobile. Marche e modelli dalle origini a oggi, vol. 6, Lancia, Roma.

Besnier M., Chapot, V. (1913), "Via”, Dictionnaire des Antiquités Grecques et Romaines, 5, Paris, 777-817.

Bettini, C. (2008), “Tre Valascos nell'Italia del quatrocento: Meser Valasco di Vespasiano da Bisticci, Petrus Vallascis di Cataldo Siculo e Vasco Fernandes de Lucena", Humanitas 60: 205-226.

Bettini, M., Boldrini, M., Calabrese, O., Piccinni, G. (eds.) (2010), Miti di città, Siena.

Binsfeld, W. (1979), "Zu treverischen Kultdenkmälern”, in Festschrift 100 Jahre Rheinisches Landesmuseum Trier. Beiträge zur Archäologie und Kunst des Trierer Landes, Mainz, 263-269.

Blackman, D. (1969), "The Athenian Navy and Allied Naval Contributions in the Pentecontaetia", GRBS 10: 179-216.

Blanco Freijeiro, A. (1977), El puente de Alcántara en su contexto historico, Madrid.

Boardman, J. (1986), I Greci sui Mari. Traffici e Colonie, Trad. ital., Firenze, Giunti.

Boffo, L. (1975), "Cimone e gli alleatidi Atene”, RIL 109: 442-50.

Bol, R. (1984). Das Statuen programm des Herodes-Atticus-Nymphäums, Berlin.

Bona, G. (ed.) (1988), Pindaro. I peani, Cuneo.

Bonfante, G., Bonfante, L. (2002), The Etruscan language. An introduction. Revised edition, Manchester and New York.

Bonneville, J.-N. (1981), "Les cupae de Barcelone: les origines du type monumental", $M C V 17$ : 5-38.

Bontems, C. (1965), Le prince dans la France des XVIe e XVIIe siècles, Paris.

Bordenache, G. (1960), "Antichità greche e romane nel nuovo Museo di Mangalia”, Dacia N. S. 4: 489-509.

Bordenache, G. (1961), "Histria alla luce del suo materiale scultureo”, Dacia N. S., 185-211.fig. 16.

Bordenache, G. (1969), Sculture greche e romane del Museo Nazionale di Antichità di Bucarest I. Statue e rilievi di culto, elementi architectonici e decorativi, Bukarest.

Boschung, D. (1993a), Die Bildnisse des Augustus, Berlin. 
Boschung, D. (1993b), “Die Bildungstypen der julisch-claudischen Kaiserfamilie: ein kritischer Forschungsbericht", JRA 6: 39-79

Boschung, D. (2002), Gens Augusta. Untersuchungen zu Aufstellung, Wirkung und Bedeutung der Statuengruppen des julisch-claudischen Kaiserbauses, Mainz.

Boucher, S. (1987), "Limage et les fonctions du dieu Sucellus", Caesarodunum 23: 77-85.

Boulanger, A. (1923), Aelius Aristide et la sophistique dans la province d'Asie au II siècle de notre ère, Paris.

Bowersock, G.W. (1969), Greek Sophists in the Roman Empire, Oxford.

Braancamp Freire A. (ed.) (1916), Notícias da Vida de André de Resende pelo Beneficiado Francisco Leitão Ferreira, Lisboa.

Bracco, V. (1985), "Il tabellarius di Polla", Epigraphica 47: 93-97.

Brandão, M. (1937), Documentos de D. João III, I, Coimbra.

Brandt, H. (1998), Geschichte der römischer Kaiserzeit. Von Diokletian und Konstantin bis zum Ende der konstantinische Dynastie (264-363), Berlin.

Briant, P. (2002), From Cyrus to Alexander. A History of the Persian Empire, Winona Lake.

Brown, B.R. (1957), Ptolemaic Paintings and Mosaics and the Alexandrian style, Cambridge.

Brown, T. S. (1946), "Euhemerus and the Historians", HThR 39: 259-274.

Brun, J.-P. (1986), L'oléiculture antique en Provence. Les huiliers du departement du Var (RANArb suppl. 15), Paris.

Brun, J.-P. (2003), Le vin et l'huile dans la Méditerranée antique. Viticulture, oléiculture et procédés de transformation, Paris.

Brun, J.-P. (2004), Archéologie du vin et de l'huile dans l'empire romain, Paris.

Brun, J.-P. (2005), Archéologie du vin et d'buile en Gaule romaine, Paris.

Bruneau, P. (1985), "Deliaca. Iconographie. L'image de Delos personifiée e pyxides de Spina”, BCH 109: 551-556.

Búa, C. (1997), "Dialectos indoeuropeos na franxa ocidental hispânica”, in G. Pereira (ed.), Galicia fai dous mil anos. O feito diferencial galego, volumen I. Historia, Santiago de Compostela, 51-99.

Buck, R. J. (1979), A History of Boeotia, Edmonton.

Bulloch, A. W (1985), Callimachus. The Fifth Hymn, Cambridge.

Bulloch, A. W (2010), "Hymns and Encomia", in J. J Clauss and M. Cuypers (eds.), A Companion to Hellenistic Literature, Malden/Oxford, 166-180.

Burazacchini, G. (ed.) (2005), Troia tra realtà e legenda, Parma.

Burckhardt J. (1949), The Age of Constantine the Great, Berkeley. 
Burke, P. (1987 3a ed.), The italian Renaissance culture and society in Italy, Cambridge.

Burkert, W. (1991), Mito e Mitologia, Ed. 70, Lisboa.

Burkhalter-Arce, F. (2002), "Le tarif de Coptos". La douane de Coptos, les fermiers de l'apostolion et le préfet du desert de Bérénice”, Topoi Supp. 3: 199-233.

Burnett, A. P. (2005), Pindar's Songs for Young Athletes of Aigina, Oxford.

Bury, J. B., Cook, S. A., Adcock ,F. E. (eds.), The Cambridge Ancient History, Vol. 4, Cambridge.

Butcher, K. (2003), Roman Syria and the Near East, London.

Buxton, R. (ed.) (1999), From Myth to Reason? Studies in the Development of Greek Thought, Oxford.

Caccamo Caltabiano, M. (2003), "Messana/Tyche sulle monete della città dello stretto", in Archeologia del Mediterraneo. Studi in onore di Ernesto De Miro, Roma, 139-149.

Cadotte, A. (2007), La romanisation des dieux. L'interpretatio romana en Afrique du Nord sous le Haut-Empire (Religions in the Graeco-Roman world 158), Leiden.

Caiado, H. (1745), Eclogae et Sylvae et Epigrammata, in Pe. A. dos Reis, Corpus illustrium poetarum Lusitanorum, qui latine scripserunt, Lisboa.

Cairns, D. L. (2010), Bacchylides: five epinician odes (3, 5, 9, 11, 13), Cambridge.

Camia, F. (2011), Theoi sebastoi. Il culto degli imperatori romani in Grecia (provincia Achaia) nel secondo secolo D.C., Athinai.

Caldera de Castro, M. D. P. (1978), "Una sepultura de cupa hallada en Mérida. (Consideraciones acerca de estos monumentos funerarios)", Habis 9: 455-463.

Calderón Dorda, E., De Lazzer, A., Pellizer, E., (eds.) (2003), Corpus Plutarchi Moralium, Naples.

Calvino, I. (1996), "Diario americano, 1959-1966”, in Eremita a Parigi. Pagine autobiografiche, Milano, 20-124.

Calvino, I. (1996a), Città invisibili, Milano.

Camargos, M. (2001), Villa Kyrial: crônica da Belle Époque paulistana, São Paulo.

Cameron A. (1993), The later Roman empire: AD 284-430, Cambridge.

Cantemir, D. (2006), The Salvation of the Wise Man and the Ruin of the Sinful World [...], ed., trans., notes, indices Ioana Feodorov, Editura Academiei, Bucuresti.

Cantemirius, D. (1973), Descriptio antiqui et hodierni status Moldaviae/ Dimitrie Cantemir, Descrierea Moldovei, trans. Gh. Gutu, introd. Maria Holban, hist. com. N. Stoicescu, cartographical study Vintilă Mihailescu, index Ioana Constantinescu, note D. M. Pippidi, Bucuresti. 
Bibliografia

Cantemirius, D. (2006), Descriptio antiqui et hodierni status Moldaviae/ Dimitrie Cantemir, Principele Moldovei, Descrierea stării de odinioară şi de astăzi a Moldovei, ed., trans. Dan Slusanschi, Bucuresti.

Cantineau, J. (1935), Grammaire du palmyrénien épigraphique, Le Caire.

Carcopino, J.(s/d), A vida quotidiana em Roma no apogeu do Império (trad A. J. Saraiva), Lisboa.

Cardim Ribeiro, J. (2002), "Soli Aeterno Lunae. O santuário", Religiões da Lusitânia. Loquuntur Saxa, Lisboa, 235-239.

Cardim Ribeiro, J. (2005), "O deus sanctus Endovellicus durante a romanidade. Uma interpretatio local de Faunus-Silvanus?”, Paleohispanica 5: 721-766.

Carlier p. (1990), Démosthène, Paris.

Carneiro, A., d'Encarnação, J., de Oliveira, J., Teixeira, Cl. (2008), "Uma iscrição votiva em lengua lusitana”, Palaeobispanica 8: 167-178.

Caro, A. (2009), “Una fase decisiva en la evolución de la publicidad: la transición del producto a la marca", Pensar la publicidad, III, 2: 109-114.

Caro, A. (2010), Comprender la publicidad, Barcelona.

Cartledge, P. (2009), Ancient Greek Political Thought in Practice, Cambridge.

Carvalho, J. de (1947-1948), Estudos sobre a cultura portuguesa do século XVI, 2 vols. Coimbra.

Carvalho, J. de (1949), Estudos sobre a cultura portuguesa do século XV, Coimbra.

Cascudo, L. C. (1974), Prelúdio e fuga do real, Natal.

Cascudo, L. C. (1983), Civilização e Cultura, pesquisas e notas de etnografia geral, Belo Horizonte.

Cascudo, L. C. (1983, 2ª ed.), Anúbis e outros ensaios. Mitologia e folclore, Rio de Janeiro, Natal.

Cascudo, L. C. (1987), História dos nossos gestos, Belo Horizonte, São Paulo.

Cascudo, L.C. (1966), "História de um livro perdido", Arquivos do Instituto de Antropologia "Câmara Cascudo" 2.1-2: 5-19.

Castelli, E. (1951) (ed.), Umanesimo e Scienza politica. Atti del congresso Internazionale di Studi Umanistici, Roma-Firenze, 1949, Milano.

Castillo, C. (1998), "Los flamines provinciales de la Bética", REA 100: 437-460

Cawkwell, G. (2005), The Greek Wars. The Failure of Persia, Oxford.

Cesarano, M. (2015), In honorem domus divinae. Introduzione allo studio dei cicli statuari giulio-claudii a Roma e in Occidente, Roma.

Clauss, M. (1979), Kaiser und Gott: Herrscherkult im romischen Reich, Berlin.

Chamie, M. (2009), Paulicéia dilacerada, Ribeirão Preto.

Chaniotis, A. (2009), "The Dynamics of Rituals in the Roman Empire", in O. 
Hekster, S. Schmidt-Hofner, Chr. Witschel (eds.), Ritual Dynamics and Religious Change in the Roman Empire. Proceedings of the Eight Workshop of International Network Impact of Empire, Leiden, Boston, 3-29

Charles-Picard, G., Rougé, J. (1969), Textes et documents relatifs à la vie economique et sociale dans l'Empire romain, Paris.

Chassaing, M. (1961), "Les barillets frontiniens“, RAE 12: 7-33, 89-106.

Chelotti, M. (2003), Regio II, Apulia et Calabria, Venusia (Supplementa Italica 20), Roma.

Cherry, D. (1998), Frontier and Society in Roman North Africa, Oxford.

Chevallier, R. (1972), Les voies romaines, Paris.

Chevallier, R. (1988), Voyages et déplacements dans l'Empire romain, Paris.

Chiarelli, G. (1932), 'Il 'De regno' di Francesco Patrizi', Rivista internazionale di filsosofia del diritto, Anno XII. (Nov-Dec.): 716-738.

Cistercienses (Os). Documentos primitivos. Texto latino e tradução brasileira. (1997) Introdução e bibliografia Irmão François de Place, Tradução de Irineu Guimarães, Musa, S. Paulo; Lúmen Christi, Rio de Janeiro 1997.

Clauss, J., Cuypers, M. (eds.) (2010), A Companion to Hellenistic Literature, Chichester, West Sussex.

Clavel-Lévêque, M. et alii (eds.) (1993), Siculus Flaccus. Les conditions des terres, Nápoles.

Clavel-Lévêque, M. et alii (eds.) (1996), Hygin l'arpenteur. L' établissement des limites, Nápoles.

Clayton, P.A. (1989), Le sette Meraviglie del mondo, Torino. (The Seven Wonders of the Ancient World, London, 1988).

Cogitore, I. (1996), “Séries de dédicaces italiennes à la dynastie julio-claudienne”, MEFRA 104 : 817-870.

Colasso, F. (1951), "Umanesimo giuridico", in E. Castelli (ed.), Umanesimo e Scienza politica (Atti dei Congresso Internazionale di Studi Umanistici, Roma-Firenze, 1949), Milano, 57-58.

Colecchia, A., Bertolani, G. B., Marcante, A. et alii (2004), L'Alto Garda occidentale dalla preistoria al postmedioevo. Archeologia, storia del popolamento e trasformazione del paesaggio (Documenti di archeologia, 36), Mantova.

Colonna, G. (1980), "Virgilio, Cortona e la leggenda etrusca di Dardano", Archeologia Classica 32: 1-15.

Conger, G. P. (1952), "Did India influence Early Greek Philosophies?", Philosophy East and West 2.2: 102-128.

Conti, S. (1997), "Dinastia giulio-claudia a Roselle: una serie di dediche imperiali in Etruria”, Ann. Fac. Lett. e Filos. Univ. Siena 18: 101-127. 
Conti, S. (1998), Rusellae, Suppl. It. n. s. 16, Roma.

Cook, J. M. (1971), Os Gregos na Iónia e no Oriente, Lisboa.

Cooley, A. E. (ed.) (2002), Becoming Roman, Writing Latin? Literacy and Epigraphy in the Roman West. JRA Suppl. Ser. 48, Portsmouth.

Cooley, A. E. (2002), "The survival of Oscan in Roman Pompeii”, in E. A. Cooley (ed.), Becoming Roman, Writing Latin? : Literacy and Epigraphy in the Roman West, JRA Suppl. Ser. 48: 77-86.

Cordovana, O. D., Galli, M. (eds.) (2007), Arte e memoria culturale nell'età della Seconda Sofistica, Catania.

Corell, J. (1989), “Notas sobre epigrafía romana del País Valenciano”, APL 19: 271-281.

Costa, A. D. S. (1969), Estudantes portugueses na reitoria do Colégio de S. Clemente de Bolonha na primeira metade do século XV, Lisboa.

Costa, A. D. S. (1990), Portugueses no Colégio de S. Clemente e Universidade de Bolonha durante o século $X V$, vol. I, Bolonia.

Coulanges, F. de. (1971, 10ª ed.), A cidade antiga, Trad. e glossário de Fernando de Aguiar, Livraria Clássica Editora, Lisboa.

Crawford, M. H., Reynolds, J. M. (1979), “The Aezani copy of the Prices Edict”, Zeitschrift für Papyrologie und Epigraphik 34: 163-210.

Crystal, D. (2000), Language death, Cambridge.

Curado, F. P. (1985), "Inscrição rupestre de Freixo de Numão”, Ficheiro Epigráfico 11: no48.

David, B., Thomas J. (eds.) (2008), Handbook of landscape archaeology (World archaeological congress research handbooks in archaeology, 1), Walnut Creek.

Davie, J. N. (1982), "Theseus the king in fifth-century Athens", GE'R 29.1: 2534.

DCPH = M. P. García-Bellido y C. Blázquez (2001), Diccionario de cecas y pueblos hispánicos, Madrid.

De Bernardo Stempel, P. (2008), "More names, fewer deities. Complex theonymic formulas and the three types of interpretation", in Divindades indígenas em análise. Divinités pré-romaines. Bilan et perspectives d'une recherche. Actas do VII workshop FERCAN, Cascais, 25-27.5.2006, Coimbra, 65-73.

De Hoz, J. (2001), "La lengua de los íberos y los documentos epigráficos en la comarca de Requena-Utiel”, in A. J. Lorrio (ed.), Los íberos en la comarca de Requena-Utiel (Valencia), Madrid, 49-62.

De Hoz, J. (2010), Historia lingüistica de la Península Ibérica en la Antigüedad. I. Preliminares y mundo meridional prerromano, Madrid. 
De Hoz, M. P. (1997), “Epigrafía griega en Hispania”, Epigraphica 59: 29-93.

De Labriolle, P. (1934), La reaction païenne, Paris.

De Martino, D. (2010), "Spot, etica e letteratura", La nuova ricerca. Pubblicazione annuale del Dipartimento di Linguistica, Letteratura e Filologia moderna dell'Università degli studi di Bari, anno XIX. 19, 117-128.

De Martino, D. (2010 bis), "Automobili da mito", in F. De Martino (ed.), Antichità Ẽ pubblicità, Bari, 443-522.

De Martino, D. (2011), Io sono Giulietta. Letterature E' miti nella pubblicità di auto, Bari.

De Martino, D. (2012), "Una forma de subversión del mito literario: de la novela a la publicidad", in J. M. Losada Goya, M. Guirao Ochoa (eds.), Myth and Subversion in the Contemporary Novel, Cambridge, 421-436.

De Martino, D. (2013), Dante E̋ la pubblicità, Bari.

De Martino, F., Vox, O. (1996) (eds.), Lirica greca, vol. 3, Bari.

De Ruyt, Cl. (1983), Macellum. Marché alimentaire des romains, Louvain-laNeuve.

De Santerre, H. H. (1976), "Athènes, Délos et Delphes d'après une peinture de vase à figure rouges du V siècle avant J.-C.”, BCH 100: 291-298.

De Vos, M., Andreoli, M., Attoui, R. et alii (2007), "Cilicia campestris orientale. Leconomia rurale e la trasformazione del paesaggio intorno al Karasis", in Geografia e viaggi nell'antichità. Atti del convegno internazionale di studi (Certosa di Pontognano, 9-10 ottobre 2005), Siena, 13-39.

Degl'Innocenti Pierini, R. (2012), "Le città personificate nella Roma repubblicana: fenomenologia di un motivo letterario tra retorica e poesia", in G. Moretti, A. Bonandini (eds.), Persona ficta. La personificazione allegorica nella cultura antica, fra letteratura, retorica e iconografia, Trento, 215-247.

Desbat, A. (1991), "Un bouchon de bois du Ier s. aprés J.-C. recueilli dans la Saône à Lyon et la question du tonneau à 1'époque romaine", Gallia 48: 319-336.

Dias, P. B. (2011 2a ed.), “Notas introdutórias”, in J. G Freire, A versãolatina por Pascásio de Dume dos Apophtegmata Patrum, Coimbra, 1-34.

Dias, P. B. (2012), “Cristianismo e responsabilidade cristã na queda de Roma”, in F. Oliveira et alli (coords.), A queda de Roma e o alvorecer da Europa, Coimbra, 43-67.

Dias P. B. (2013), "O legado de Constantino na identidade da Europa cristã: dois casos de estudo", in M. C. Pimentel e P. Farmhouse Alberto (orgs.), Vir bonus peritissimus aeque. Estudos de homenagem a Arnaldo do Espirito Santo, Lisboa, 455-463 
Díaz, B. (2008), Epigrafía latina republicana de Hispania, Barcelona.

Dittenberger, W., Purgold, K. (1896), Inschriften von Olympia, Berlin.

Dixon, R. M. W. (1997), The rise and fall of languages, Cambridge.

Domăneanțu, C. (1993), "Un sanctuaire hellénistique du site de Nuntaşi II (comm. d'Istria, dep. De Constanța)”, Dacia 37: 59-78.

Dörfler, W., Evans, A., Löhr, H. (1998), “Trier, Walramsneustrasse. Untersuchungen zum römerzeitlichen Landschaftswandel im Hunsrück-Eifel-Raum an einem Beispiel aus der Trierer Talweite“, in Studien zur Archäologie der Kelten, Römer und Germanen in Mittel- und Westeuropa. Alfred Haffner zum 60. Geburtstag gewidmet, Rahden, 119152.

Dubuisson, M. (1981), "Utraque lengua”, L'Antiquité Classique 50: 274-286.

Dubuisson, M. (1982), "Y a-t-il une politique linguistique romaine?”, Ktéma 7: 197-210.

Duchesne, L. (1887), "Le concile d'Elvire et les flamines chrétiens", Mélanges Renier, Paris, 159-174.

Dunkle, J. R. (1969), “The Aegeus episode and the theme of Euripides' Medea", TAPhA 100: 97-107.

Durán Fuentes, M. (2005), La construcción de puentes romanos en Hispania, Santiago de Compostela.

Eck, W. (2006), "Herrschaft und Kommunikation in antiken Gesellschaften. Das Beispiel Rom", in U. Peter, S. J. Seidlmayer (eds.), Mediengesellschaft Antike? Information und Kommunikation vom Alten Ägypten bis Byzanz, Berlin, 11-33.

Eco, U. (2013), Storia delle terre e dei luoghi leggendari, Milano.

Eddy, S.K. (1968), “Four Hundred Sixty Talents Once More”, CP 63: 184-95.

Edmonson, J. (1997), “Two dedications to Divus Augustus and Diva Augusta from Augusta Emerita and the early development of the imperial cult in Lusitania", MM 38: 89-105.

Edmondson, J. (2002), "Writing latin in the province of Lusitania", in A. E. Cooley (ed.), Becoming Roman, Writing Latin? Literary and Epigraphy in the Roman West, JRA Suppl. Ser. 48: 41-60.

Ehrenberg, V. (1973, 2a ed.), From Solon to Sócrates, Londres.

Ehrenberg, V. (1976), L'État grec, Paris.

Ehrhardt, N. (1988), Milet und seine Koloniei. Vergleichende Untersuchung der kultischen und politischen Einrichtungen, ed. a II-a, Frankfurt, Main-Bern, New York, Paris.

Elliger, W. (1975), Die Darstellung der Landschaft in der griechischen Dichtung, Berlin, New York. 
Elliott, Th. (1990), “The Language of Constantinian Propaganda”, TAPhA 120: 349-353.

Encarnação, J. d' (1984), Inscrições romanas do Conventus Pacensis, Coimbra.

Erasmo, D. (1703), Opera omnia (in decem tomos distincta), Recognovit Joannes Clericus, Leiden.

Erodoto (1988), Le Storie. Libro I. La Lidia ela Persia. Acura di David Astheri, Milano.

Erskine, A. (ed.) (2003), A Companion to the Hellenistic World, Oxford.

Espérandieu, E. (1907-1981), Recueil général des bas-reliefs, statues et bustes de la Gaule romaine, Paris.

Estarán, M. J. (2012), “Las estampillas ibérico-latinas K.5.4”, Palaeohispanica 12: $73-90$

ET = Rix, H. (1991), Etruskische Texte, Tübingen.

Étienne, R. (1958), Le culte impérial dans la Péninsule ibérique d’Auguste à Diocletien, Paris.

Étienne, R. (1973), "Les syncrétismes dans la Péninsule Ibérique à l'époque impériale", in Les syncrétismes dans les religions grecque et romaine, Paris, 153-163.

Étienne, R., Fabre, G.; Lévêque, P. et M. (1976), Fouilles de Conimbriga, vol. II, Épigraphie et Sculpture, Paris.

Étienne, R., Fabre, G., Le Roux, P., Tranoy, A. (1976), "Les dimensions sociales de la romanisation dans la Péninsule Ibérique des origines à la fin de l'Empire", in D. M. Pippidi (ed.), Assimilation et résistance à la culture gréco-romaine dans le monde ancien. Travaux du VI Congrès International d'Études Classiques, Bucureşti, Paris, 95-107.

Étienne, R., Mayet, F. (2000), Le vin hispanique, Paris.

Evans, J. A. S. (1981), "Notes on the debate of the Persian Grandees in Herodotus 3, 80-82”, QUCC 36: 79-84.

Evers, C. (1994), Les portraits d'Hadrien. Typologie et ateliers, Bruxelles.

Ewald, C., Norena, C. F. (eds.) (2010), The Emperor and Rome: Space, Representation, Ritual, Cambridge.

Fabre, G., Mayer, M., Rodà, I. (1991), Inscriptions romaines de Catalogne, III, Paris.

Fayer, C. (1976), Il culto della dea Roma. Origine e diffusione nell'Impero, Pescara.

Fearn, D. (2007), Bacchylides. Politics, performance, poetic tradition, Oxford.

Fernandes, L., Carvalho, P., Figueira, N. (2009), "Divindades indígenas numa ara inédita de Viseu", Palaeohispanica 9: 143-155.

Fernández Gallardo, L. (2002), Alonso de Cartagena. Una biografía politica en la Castilla del siglo XV, Valladolid. 
Fernández Gallardo, L. (2008), “Alonso de Cartagena y el Humanismo”, La Corónica 37.1: 175- 215.

Ferraz, C. (2002), "Conjunto de oito aras provenientes do Lararium de Centum Celas", in V. L. Raposo, J. R. Ferreira (Coords.), Religióes da Lusitânia. Loquuntur Saxa, Lisboa, 467-469.

Ferreira, J. R. (1988), "Grécia e Roma na Revolução Francesa”, Revista de História das Ideias 10: 203-234.

Ferreira, J. R. (1990), A democracia na Grécia Antiga, Coimbra.

Ferreira, J. R. (1990a), Participação e poder na democracia grega, Coimbra.

Ferreira, J. R. (1993), Hélade e Helenos I - Génese e Evolução de um Conceito, Coimbra.

Ferreira, J. R. (2004 2a ed.), A Grécia Antiga. Sociedade e Politica, Lisboa.

Ferreira, J. R., (1991), "Presença da Grécia e de Roma na Revolução Francesa", in Actas do colóquio A Recepção da Revolução Francesa em Portugal e no Brasil, Porto, vol. I, 75-96.

Ferri, S. (1976), "Luci e ombre sulla interpretatio romana", in Convegno internazionale "Renania romana" Roma 14-16 aprile 1975, Roma, 125133.

Ferrill, A. (1978), "Herodotus on tyranny", Historia 27.3: 385-398.

Figueira, T. J. (1998), The Power of Money: Coinage and Politics in the Athenian Empire, Philadelphia.

Figueira, T. J. (2003), "Economic Integration and Monetary Consolidation in the Athenian Arkhê", in G. Urso (ed.), Moneta, Mercanti, Banchieri. I precedenti greci e romani dell'Euro, Pisa, 71-92.

Figueira, T. J. (2005), "The Imperial Commercial Tax and the Finances of the Athenian Hegemony”, Incidenza dell'antico 3: 83-133.

Figueira, T. J. (2006), "Reconsidering the Athenian Coinage Decree", AIIN 52: 9-44.

Figueira, T. J. (2011), "The Athenian Naukraroi and Archaic Naval Warfare”, Cadmo. Revista de História Antiga 21: 183-210.

Figueira, T. J. (forthcoming[a]), "Archaic Naval Warfare”, in N. Birgalias (ed.), Great is the Power of the Sea: The Power of Sea and Sea Powers in the Greek world of the Archaic and Classical Periods, Athens.

Figueira, T. J. (forthcoming[b]), "The Aristeidian Tribute on the Peace of Nikias", in S. Jensen, T. Figueira (eds.), Athenian Hegemonic Finances, Swansea.

Figueira, T. J. (forthcoming[c]), "Community Wealth and Military Might in Periclean Athens", in A.L. Pierris (ed.), Mind, Might, Money: The Secular Triad in Classical Athens, Patras. 
Figueira, T. J. (forthcoming[d]), “Aigina: Island as Paradigm”, in A. Powell and K. Meidani (eds.), The Eyesore of Aigina: Anti-Athenian Attitudes in Greek, Hellenistic and Roman History, Swansea.

Figueiredo, R., Lamounier, B. (1996), As cidades que dão certo, Brasília.

Finley, M.I. (1966), The Ancient Greeks. An introduction to their life and thought, Londres. Trad. port.: Os Gregos Antigos (Lisboa, 2a ed. 1988).

Finley, M. I. (1973, 2a ed.), Democracy, ancient and modern, London.

Finley, M.I. (1973a), The ancient economy, London.

Finley, M.I. (1982), Authority and legitimacy in the classical city-state, Kobenhavn.

Fishwick, D. (1970), "Flamen Augustorum”, HSCPh 74: 299-312.

Fishwick, D. (1982), "The altar of Augustus and the municipal cult of Tarraco", MM 23: 222-233

Fishwick, D. (2002), The Imperial Cult in the Latin West, 3/2, Provincial Cult I The Provincial Priesthood, Leiden.

Fishwick, D. (2005), The Imperial Cult in the Latin West. Studies in the Ruler Cult of the Western Provinces of the Roman Empire, Leiden, Boston.

Fitton, J. W. (1961), "The Suppliant Women and the Herakleidai of Euripides", Hermes 89.4: 430-461.

Flower, M. F. (2007), "Appendix R: The Size of Xerxes Expeditionary Force," in Robert B. Strassler (ed.), The Landmark Herodotus: The Histories, New York, 819-23.

Fonseca, L. A. (1982), O Condestável D. Pedro de Portugal, Porto.

Fontanella, F. (2008), "The Encomium on Rome as a response to Polybius' doubts about the Roman Empire", Columbia Studies in the Classical Tradition 33: 203-216.

Forni, G. (1973), "El culto de Augusto en el compromiso oficial y en el sentimiento oriental", BSAA 39: 105-113.

Forni, G. (1994), Scritti vari di Storia, Epigraphia e antichità romane, Roma.

Franck, A. D. (1864), Réformateurs et publicistes de l'Europe: Moyen ÂgeRenaissance, Paris.

French, A. (1972), "The Tribute of the Allies", Historia 21: 3-20.

Fuentes, M. J. (1986), Corpus de las inscripciones fenicias, púnicas y neopúnicas de Hispania, Barcelona.

Gabba, S., Drioton, É. (1954), Peintures à fresques et scènes peintes a Ermoupolis Ouvest (Touna el-Gevel), Le Caire.

Gaffiot, F. (s/d), Dictionnaire latin-français, Paris.

Gagé, J. (1936), "Le templum Urbis et les origines de l'idée de Renovatio", in Mélanges Franz Cumont, Bruxelles, 151-187. 
Gagé, J. (1955), Apollon romain. Éssai sur le culte d'Apollon et le développement du "ritus Graecus" à Rome des originrs à Auguste, Paris.

Gagé, J. (1968), "Basiléia”. Les Césars, les rois d'Orient et les "mages", Paris.

Gagé, J. (1974), "Le solemne Urbis du 21 avril au III" siècle ap. J.-C.: Rites positives et speculations séculaires", Mélanges d'histoire de religions offerts à Henri-Charles Puech, Paris, 225-241.

García Bellido, M. P. (1993), "Sobre el culto de Volcanus y Sucellus en Hispania. Testimonios numismáticos", in F. Burkhater, J. Arce (eds.), Bronces y religión romana. Actas del XI Congreso internacional de bronces antiguos, Madrid mayo - junio 1990, Madrid, 161-170.

García Iglésias, L. (1976), "Autenticidad de la inscripción de municipios que sufragaron el puente de Alcántara”, Revista de Estudios Extremeños 32.2: 263-276.

García Jurado, F. (2007), Aulo Gelio, Noches Aticas. Antología, Madrid.

García Romero, F. (2002), "Pervivencia de Penélope”, in C. Morenilla Talens, F. De Martino (eds.), El perfil de les ombres, Bari, 187-204.

García Soler, M. J. (2010), "Gastronomia e pubblicità nella Grecia antica”, in F. De Martino (ed.), Antichità Ẻ pubblicità, Bari, 345-366.

Garin, E. (1955), "Ricerche sulle traduzioni di Platone nella prima metà del XV secolo", Medioevo e Rinascimento, Studi in onore di B. Nardi, Firenze.

Garin, E. (1966), Storia della filosofia italiana, Torino.

Garriguet, J. A. (2004), "Grupos estatuarios imperiales de la Bética: la evidencia escultórica y epigráfica”, in Actas de la IV reunión sobre escultura romana en Hispania, Madrid, 67-101.

Gasperini, L. (1977), “L’Augusteo di Firmo Piceno in un'epigrafe da rileggere”, AFML 10: 57-87.

Gasperini, L. (2008), "L’Augusteo di Forum Clodii”, en L. Gasperini, G. Paci, (eds.), Nuove ricerche sul culto imperiale in Italia, Tivoli, 91-134.

Gasperini, L., Paci, G. (eds.) (2008), Nuove ricerche sul culto imperiale in Italia, Tivoli.

Gaudemet J. (1947), “La législation religieuse de Constantin”, Rérue d' Histoire de l'Église de France 122: 25-61.

Genette, G. (1997), Palinsesti. La letteratura di secondo grado, Torino.

Gentili, B. (ed.) (1995), Pindaro. Le pitiche, Milano.

Ghedini, F. (2000), "Filostrato Maggiore come fonte per la conoscenza della pittura antica”, Ostraka 9.1: 75-197.

Giachero, M. (ed.) (1974), Edictum Diocletiani et Collegarum de pretiis rerum venalium in integrum restitutum e latinis gracisque fragmentis, 1-2, Génova. 
Gico, V. (1998), "Luís da Câmara Cascudo: perfil bibliográfico", in L. C. Cascudo, Ontem. (Maginaçôes e notas de um professor de provincia), Natal.

Gigli, D. (1985), Metafora e poetica in Nonno di Panopoli, Firenze.

Gilles, K. J. (1987), "Römische Glasgefäße", in AA.VV., 2000 Jahre Weinkultur an Mosel-Saar-Ruwer. Denkmäler und Zeugnisse zur Geschichte von Weinbau, Weinhandel, Weingenuß, Trier, 143-145.

Gilles, K. J. (1987b), “Trierer Weinkeramik”, in AA.VV., 2000 Jabre Weinkultur an Mosel-Saar-Ruwer. Denkmäler und Zeugnisse zur Geschichte von Weinbau, Weinhandel, Weingenuß, Trier, 132-133.

Gilles, K. J., König, M., Schumann, F. (1995), Neuere Forschungen zum römischen Weinbau an Mosel und Rhein (Schriftenreihe des Rheinischen Landesmuseums Trier, 11), Trier.

Gilson, É. (1983, 6ª ed.), Le thomisme, Paris.

Gómara, M. (2007), "Una inscripción paleohispánica sobre cerámica altoimperial en Cascante (Navarra)", Palaeohispanica 7: 263-268.

Gomes, S.A. (1998), Visitações a mosteiros cistercienses em Portugal. Séculos XVe XVI, Ministério da Cultura - IPPAR, Lisboa.

Gomes, S. A. (2000), "Revisitação a um velho tema: a fundação do Mosteiro de Alcobaça”, in Cister: Espaços Território e Paisagens. Colóquio Internacional, 16-20 Junho de 1998, Mosteiro de Alcobaça. Actas. I, Lisboa, 27-72.

Gomes, S. A. (2000), O mosteiro de Alcobaça na transição dos séculos XIV e XV: o protagonismo de D. João Dornelas, in Cister. Espaços, Territórios, Paisagens. Colóquio Internacional. 16-20 Junho 1998. Mosteiro de Alcobaça, Lisboa, 73-88.

Gomes, S. A. (2006), D. Afonso V, Círculo de Leitores-Colecção Reis de Portugal, Lisboa.

Gómez García, C. (2010), "La configuración de la ciudad de Berlin”, in J. M. Losada Goya (ed.), Mito y mundo contemporáneo. La recepción de los mitos antiguos, medievales y modernos en la literatura contemporánea, Bari , 617626.

González Rolán, T., P. Saquero Suárez-Somonte, P. (2001), “E1 Humanismo italiano en la Castilla del cuatrocientos: estudio y edición de la versión castellana y del original latino del De infelicitate principum de Poggio Bracciolini “, Cuadernos de Filología Clásica. Estudios Latinos 21: 115-150.

González Rolán, T., Moreno Hernández, A., Saquero Suárez-Somonte, P. (2000), Humanismo y teoría de la traducción en España e Italia en la primera mitad del siglo XV. Edición y estudio de la Controversia Alphonsiana (Alfonso de Cartagena vs. L. Bruni y P. Candido Decembrio), Madrid.

Gorrochategui, J. (1987), "Situación lingüística de Navarra y aledaños en la antigüedad a partir de las fuentes epigráficas", Primer Congreso General de Historia de Navarra II, Pamplona, 435-445. 
Gorrochategui, J. (2014), "Nueva inscripción funeraria celtibérica procedente de Clunia”, Palaeobispanica 14: 229-236.

Gorrochategui, J.y Vallejo, J. M. (2010), “Lengua y onomástica. Las inscripciones lusitanas", Iberografías 6: 71-80.

Gose, E. (1976), Gefäßtypen der römischen Keramik im Rheinland, Köln.

Graham, A.J. (1964), Colony and Mother City, Manchester.

Grenier, A. (1934), Manuel d'archéologie gallo-romaine 2, Les routes, Paris.

Gros, P., Marin, M., Zink, M. (eds.) (2015), Auguste, son époque et l'Augusteum de Narona. Actes du colloque organisé à l 'Académie des Inscriptions et Belles-letres le 12 décembre 2014, Paris.

Gualandi, M. L. (2001), Le fonti per la storia dell'arte - I. L'antichità classica, Roma.

Guarducci, M. (1974), Epigrafia greca, vol. III, Roma.

Guarducci, M. (1978), Epigrafia greca, vol. IV, Roma.

Guerra, A., Schatner, T. (2010), "El foro y el templo de Lancia Oppidana: nueva interpretación de Centum Celas (Belmonte)", in T. Mogale Basarrate (ed.) Ciudad y Foro en Lusitania Romana, Mérida, 333-342.

Guilaine, J. (cur.) (1991), Pour une archéologie agraire: à la croisée des sciencies de l'homme et de la nature, Paris.

Guilmartin, J. F. (2002), Galleons and Galleys, London.

Guilmartin, J. F. (2003), Gunpowder and Galleys. Changing Technology and Mediterranean Warfare at Sea in the Sixteenth Century, 2nd ed., Annapolis.

Hall, J. M. (1997), Ethnic identity in Greek Antiquity, Cambridge.

Hanell, K. (1934), Megarische Studien, Lund.

Hänlein-Schäfer, H. (1985), Veneratio Augusti. Eine Studie zu den Tempeln der ersten römischen Kaisers, München.

Hanley, R. (2000), Villages in Roman Britain, Princes Risborough.

Hansen, H. M. (1991), The Athenian Democracy in the age of Demosthenes. Structure, Principles and Ideology, Oxford.

Hardy, E. G. (1925), "The Lex Mamilia Roscia Peducaea Alliena Fabia”, The CQ 19 (3/4): 185-191.

Harris, E. (1995), Aeschines and Athenian Politics, Oxford.

Harth, H. (1984), Poggio Bracciolini, Lettere, Leo S. Olschki Editore, Florencia.

Hekster, O., Schmidt-Hofner, S., Witschel, Chr. (eds.) (2009), Ritual dynamics and Religious Change in the Roman Empire. Proceedings of the Eighth Workshop of the International Network Impact of Empire, Leiden, Boston.

Helck, W. (1971), Das Bier im alten Ägypten, Berlin. 
Hershowitz, A., (forthcoming), "Patterns in Variation in Tribute Assessment", in S. Jensen, T. Figueira (eds.), Athenian Hegemonic Finances, Classical Press of Wales, Swansea.

Herta, P. (1978), "Bibliographie zum römischer Kaiserkult (1955-1975)", ANRW II 18: 833-910.

Heubeck, A. (ed.) (1983), Omero. Odissea, Volume III (Libri IX-XII), Milano.

Heurgon, J. (1950-1951), "La syntaxe des routiers romains", Bulletin de la Société des Antiquaires de France: 145-154.

Heurgon, M. (1969), "Inscriptions étrusques de Tunisie”, CRAI, 526-551.

Heurgon, M. (1969a), “Les Dardaniens en Afrique”, REL 47: 284-294.

Higbie, C. (2007), "Hellenistic Mythographers", in R. Woodart (ed.), The Cambridge Companion to Greek Mythology, Cambridge, 237-54.

Hignett, C. (1963), Xerxes' Invasion of Greece, Oxford.

Hoffmann, C. (1991), An introduction to bilingualism, London, New York.

Hoffmann, M. (1956), 5000 Jahre Bier, Berlin.

Holban, M., Bulgaru, M. M. A., Cernovodeanu, P. (eds.) (1980-83), Calatori straini despre tarile române (Foreign Travellers about the Romanian Countries), Bucuresti, vol. VII: 1980; vol. VIII: 1983.

Homo, L. (1972), Rome impériale et l'urbanisme dans l'antiquité, Paris.

Hopkinson, N. (1984), “Callimachus' Hymn to Zeus”, CQ 34: 139-148.

Hornblower, S. (2008), A Commentary on Thucydides. Volume I: Books I-III, Oxford - New York.

Houaiss, A. (2001), Dicionário Houaiss da lingua portuguesa, Rio de Janeiro.

Howgego, Chr, Heuchert, V. Burnett, A. (eds.) (2004), Coinage and identity in the Roman provinces, Oxford.

Howgego, Chr. (2004), "Coinage and identity in the Roman provinces", in Chr. Howgego, A. Heuchert y Burnett (eds.), Coinage and identity in the Roman provinces, Oxford, 1-18.

Huizinga, J. (1948), Le déclin du Moyen Âge, Paris.

Hunter, R., Fuhrer, T. (2002), "Imaginary Gods? Poetic Theology in the Hymns of Callimachus", in F. Montanari, L. Lehnus (eds.), Callimaque. Sept Exposés suivis de discussions, Vandoeuvros-Gender, 143-175.

Hurlet, F. (1996), Les collègues du prince au temps d'Auguste et de Tibére: de la légalité républicaine à la légitimité dynastique, Roma.

Hutchinson, G. O. (1988), Hellenistic Poetry, Oxford.

HCT = Gomme, A. J., (1970), A Historical Commentary on Thucydides. vs. 1-2, Oxford. 
Icks, M. (2001), "Priestohood and Imperial Power. The Religious Reforms of Heliogabalus 220-222", in L. de Blois (ed.), Administration, Prosopography and Appointment Policies in the Roman Empire. Proceedings of the First Workshop of the International Network Impact of Empire (Roman Empire, 27 B.C. - A.D. 406), Amsterdam, 169-178.

$I R T=$ Reynolds , J. M., Ward-Perkins, J. B. (1952), Inscriptions of Roman Tripolitania, Rome.

Jackson. K. (1953), Language and history in Early Britain, Edinburgh.

Jacoby, F. (1923), Die Fragmente der griechischen Historiker, Part I-III, Berlin.

Jaeger, W. (s.d), Paideia, Trad. de Artur M. Parreira, São Paulo.

Janko R. (1982), Homer, Hesiod and the Hymns, Cambridge.

Jiménez, A. J. (1995), "La imagen de Teseo en las Suplicantes", in J. A. López Férez (ed.), De Homero a Libanio, Madrid, 145-161.

Johnson, L. (1960), "Natalis urbis and principium anni", TPAPhA 91: 109-120

Julia, D. (1962), "Les monuments funéraires en forme de demi-cylindre dans la province romaine de Tarragonaise", MCVI : 29-54.

Jullian, C. (1926), "Notes gallo-romaines”, Rérue des Études Anciennes 28. 2: 139-151.

Little, K. (2002), "Monasticism and Western Society: from marginality to the establishment and back", Memoirs of the American Academy in Rome 47: 83-94.

Kaimio, J. (1979), The Romans and the Greek Language, Helsinki.

Kalinowski, A. (2007), "A series of honorific statue bases for the Vedii in the market agora at Ephesos (IvE 725, 731, 3076-3078)", in M. Mayer, G. Baratta, A. Guzmán, (eds.), Acta XII Congressus internationalis epigraphiae Graecae et Latinae. Provinciae imperii Romani inscriptionibus descriptae, vol I, Barcelona, 757-762.

Kantiréa, M. (2007), Les dieux et les dieux augustes. Le culte impérial en Grèce sous le Julio-claudiens et les Flaviens, Études épigraphiques et archéologiques, Athènes.

Katz, S. H., Fleming, S. J., McGovern, P. E. (1996), The origins and ancient history of wine. Food and nutrition in history and anthropology 11, Amsterdam.

Kelso W.M. (ed.) (1990), Earth patterns. Essays in landscape archaeology, Charlottesville.

Kerkhecker, A. (1999), Callimachus' Book of "Iambi", Oxford.

Khanoussi, M. (1983), “Nouvelles sépultures d'époque romaine”, in Beschaouch A. et alii (eds.), Recherches archéologiques franco-tunisiennes à Bulla-Regia, I (CEFR 28/I), Roma, 93-106.

Kiss, Z. (1975), L'iconographie des princes julio-claudiens au temps d'Auguste et de Tibère, Varsovie. 
Kleiner, F. S. (1991), "The trophy on the bridge and the Roman triumph over nature", L'Antiquité Classique 60: 182-192.

Koch, J. (2009), Tartessian. Celtic in the South-west at the dawn of history, Aberystwyth.

Koch, J. (2009a), "A case for Tartessian as a Celtic language", Palaeohispanica 9: 339-351.

Kolb, A. (2001), "Tansport and communication in Roman state: the cursus publicus", in C. Adams and R. Laurence (eds.), Travel and Geography in the Roman Empire, Londres - Nova Iorque, 95-105.

Kolb, A. (ed.) (2010), Augustae. Machtbewusste Frauen am römischen Kaiserhof? Herrschaftsstrukturen und Herrschaftspraxis, Berlin.

Kozakai, T. (2000), L'étranger, l'identité. Essai sur l'integration culturelle, Paris.

Kramer, N., Reitz, Chr. (eds.) (2010), Tradition und Erneuerung. Mediale Strategien in der Zeit der Flavier, Berlin, New York.

Kristeller, P. O. (1961, 3a ed.), “The moral thought of Renaissance humanism”, in Chapters in Western civilization, I, New York, 289-335.

Krynen, J. (1981), Idéal du prince et pouvoir royal en France à la fin du Moyen Âge (1380-1440). Étude de la littérature politique du temps, Paris.

Kuhoff, W. (2001), Diokletian und die Epoche der Tetrarchie, Frankfurt.

Künzl, S. (1997), Die Trierer Spruchbecherkeramik. Dekorierte Schwarzfirniskeramik des 3. und 4. Jahrbunderts (Beihefte Trierer Zeitschrift 21), Trier.

Lambert, P. Y. (1994), La langue gauloise, Clamecy.

Lambrino, S. (1937), "La famille d'Apollon à Histria”, Aephem 100: 352-362.

Lambrino, S. (1952), "Les inscriptions de São Miguel de Odrinhas”, Bulletin des Études Portugaises 16: 134-176.

Lasserre, F. (1976), "Hérodote et Protagoras: le débat sur les constitutions", $M H$ 33: 65-84.

Lateiner, D. (1984), "Herodotean historiographical patterning: the constitutional debate", QS 20: 257-284.

Laurence, R. (2001), "Afterword: travel and empire", in C. Adams and R. Laurence (eds.), Travel and Geography in the Roman Empire, Londres / Nova Iorque, 167-176.

Lausberg, H. (1990, 3a ed.), Handbuch der literarischen Rhetorik. Eine Grundlegung der Literaturwissenschaft, Stuttgart.

Lawrance, J. N. H. (1990), "Humanism in the Iberian Peninsula", in A. Goodman, A. Mackay (eds.), The Impact of Humanism on Western Europe, Londres, 220-258.

Lazenby, J. F. (1993), The Defence of Greece, 490-479 B.C., Warminster. 
Leão, D. F. (2012), A Globalização no Mundo Antigo. Do Polites ao Kosmopolites, Coimbra.

Lehmann, K. (1962), "Ignorance and search in the villa of the Mysteries", JRS 52: $62-68$.

Leite de Vasconcelos, J. (1913), Religióes de Lusitania, III, Lisboa 1989.

Leite, S. (ed.) (1963), Estatutos da Universidade de Coimbra (1559), Coimbra.

Lekai, L. J. (1987), Los Cistercienses. Ideales y realidad, Barcelona.

Lemny, S. (2010), Cantemirestii. Aventura europeana a unei familii princiare din secolul al XVIII-lea (Les Cantemir: l'aventure européenne d'une famille princière au XVIIIe siècle, 2006), Iasi, Polirom.

Lesky, A. (1995), História da Literatura Grega, Lisboa.

Leveau, Ph. (1992), "Le territoire agricole d'Arles dans l'antiquité. Relecture de l'histoire économique d'une cité antique à la lumiere d'une histoire du milieu”, in M. Bernardi (cur.), Archeologia del Paesaggio, Firenze, vol. II, 597-636.

Levy, A. M. (2010), Sex Acts in Early Modern Italy: Practice, Performance, Perversion, Punishment, Farnham.

Lewis, D. M, Boardman, J., Hornblower, S., Ostwald, M (eds.) (1994), The Cambridge Ancient History, Volume 6: The Fourth Century BC, Cambridge.

Lewis, D. M. (1994), “The Athenian Tribute Quota Lists, 453-450 BC”, BSA 89: 285-301.

Lima, D. C. (1998, 3a ed.), Câmara Cascudo: um brasileiro feliz. Rio de Janeiro.

Lintott, A. (1992), Judicial reform and land reform in the Roman Republic, Cambridge.

Little K. (2002), "Monasticism and Western Society: from marginality to the establishment and back", Memoirs of the American Academy in Rome 47: 83-94.

Littman, R. J. (1974), The Greek experiment, Imperialism and social conflict 800400 B. C., Londres.

Liverani, P. (1994), "Il ciclo di ritratti del edificio absidato a Roselle", in Roselle: iconografia imperiale e glorificazione Familiare, MDAI, RA 101: 161-163.

Loeschcke, S. (1932), "Römische Denkmäler vom Weinbau an Mosel, Saar und Ruwer", TrZ 7: 42-60.

Loeschcke, S. (1933), Denkmäler vom Weinbau aus der Zeit der Römerherrschaft an Mosel, Saar und Ruwer, Trier.

López Moreda, S. (2009), Aulo Gelio, Noches Aticas, Madrid.

López Vilar, J. (1999-2000), “Consideracions sobre les cupae i altres estructures funeràries afins”, Bullettí Arcqueològic V. 21-22: 65-103. 
Lorenzo Gómez, F. (2010), Un dios entre los hombres. La adoración a los emperadores romanos en Grecia, Barcelona.

Losada Goya, J. M. (ed.) (2010), Mito y Mundo contemporáneo. La recepción de los mitos antiguos, medievales y modernos en la litetatura contemporânea, Bari.

Lucet, B. (1977), Les codifications cisterciennes de 1237 et de 1257, Paris.

Macan, R.W. (1908), Herodotus, The Seventh, Eighth, E Ninth Books, London.

Machado de Assis, J. M. (1971), "Esaú e Jacó", in Machado de Assis, Obra Completa, Rio de Janeiro, José Aguilar Editora.

Maehler, H. (1982), Die Lieder des Bakchylides I (2 vols.), Leiden.

Magioncalda, A. (1991), Lo sviluppo della titolatura imperiale da Augusto a Giustiniano attraverso le testimonianze epigrafiche, Torino.

Magueijo, C. (1970), “A Lex Metallis Dicta”, O Arqueólogo Português série 3, 4: 125-163.

Maltese, V. E.-Cortassa, G. (eds.)(2000), Roma parte del cielo. Confronto tra l'Antica e la Nuova Roma di Manuele Crisolora, Torino.

Mamede, Z. (1970), Luis da Câmara Cascudo: 50 anos de vida intelectual 1918/1968, Natal.

Manconi, D., Catalli, F. (eds.) (2005), Le immagini del potere. Il potere delle immagini. L'uso del ritratto ufficiale nel mondo romano da Cesare ai Severi, Perugia.

Mann, C. (2001), Athlet und Polis im archaischen und frübklassischen Griechenland, Göttingen.

Mantas, V. G. (2008-2009), "A rede viária romana em Portugal. Estado da questão e perspectivas futuras", Anas 21-22: 245-272.

Mantas, V. G. (2011), "Linhas fortificadas e vida quotidiana: da Muralha da China à Muralha do Atlântico", in C. Guardado da Silva (coord.), A Vida quotidiana nas Linhas de Torres Vedras, Torres Vedras, 15-56.

Mantas, V. G. (2012), As vias romanas da Lusitânia, Mérida.

Maquiavel, N. (2010, 8ª ed), O principe, Trad. de Pietro Nassetti, Martin Claret, São Paulo.

Maquiavel, N. (1980), Le Prince de Maquiavel, Traduction et commentaire de C. Roux-Lehman, Paris.

Maravall, J. A. (1972), Estado moderno y mentalidad social (siglos XV a XVII), 2 vols., Madrid.

Marco, F. (1993), "Nemedus Augustus", in I. J. Adiego, J. Siles, J. Velaza, (eds.), Studia Palaeohispanica et Indogermanica J. Untermann ab amicis Hispanicis oblata, Barcelona, 163-178. 
Marco, F. (1996), "Integración, interpretatio y resistencia religiosa en el occidente del imperio", in J. M. Blásquez, J. Alvard (ed.) La romanización en Occidente, Madrid, 217-238.

Marcos Casquero, M. A., Domínguez García, A. (2006), Aulo Gelio, Noches Áticas, vol. I, Universidad de León.

Marcy, G. (1936), Les inscriptions libyques bilingues de l'Afrique du nord, Paris.

Moreno Gallo, I. (2006),Vias romanas: ingenieria y técnica constructiva. Madrid.

Marlière, É. (2001), Le tonneau en Gaule Romaine», Gallia 58: 181-201.

Marlière, É. (2002), L'outre et le tonneau dans l'Occident romain, Montagnac.

Marques, M. A. F. (1998), "A introdução da Ordem de Cister em Portugal”, in Estudos sobre a Ordem de Cister em Portugal, Lisboa.

Marrou, H.-I. (1963), "L'Église dans la première moitié du quatrième siècle”, in L'Église de l'Antiquité tardive 303-604, Paris, 26-35.

Marrou, H.-I. (1965, 6ª ed.), Histoire de l'éducation dans l' Antiquité, Paris.

Marshall, P. K (1983), "Aulus Gellius", in L.D. Reynolds (ed.), Texts and Transmission. A Survey of the Latin Classics, Oxford.

Martínez, A. (1993), "Dos esgrafiados ibéricos sobre una estela romana de Requena (Valencia)", Saguntum 26: 247-251.

Martínez-Pinna, J. (2002), "Los arcadios", in La prebistoria mitica de Roma, Gerión. Anejos 6: 135-167.

Martini, W. (1990), Die archäischen Plastik der Griechen, Darmstadt.

Mastino, A. (1981), Le titolature di Caracalla e Geta attraverso le iscrizioni (indici), Bolonia.

Mattoso, A., (1935 2a ed.), Compêndio de história antiga, Sá da Costa, Lisboa.

Maurice, F. (1930), "The Size of the Army of Xerxes in the Invasion of Greece 480 B.C.", JHS 50: 210-35.

Mayer, M. (1980), "La plasmación lingüística de la pervivencia de los cultos prerromanos en Hispania a través de los formularios epigráficos", Revista Española de Lingüistica 10: 230-231.

Mayer, M. (1993), "El paganismo cívico de los siglos II y III en la Hispania citerior. Su reflejo en la epigrafía", in Ciudad y comunidad civica en Hispania. Siglos II y III d. C. Cité et communauté civique en Hispania, Madrid, 161-175.

Mayer, M. (1995), "El primer horizonte epigráfico en el litoral noreste de la Hispania citerior", in F. Beltrán (ed.), Roma y el nacimiento de la cultura epigráfica en Occidente, Zaragoza, 97-119.

Mayer, M. (1998), “¿Qué es un Augusteum?, Historia Antiqua 4: 63-70.

Mayer, M. (1999), “Aproximación a la religión cívica en Hispania bajo los 
flavios", Ktema 24: 341-345.

Mayer, M. (2004), "El Augusteum de Narona (Vid, Metković, Croacia) en época de los Severos", in Orbis Antiquus. Studia in honorem Ioannis Pisonis, ClujNapoca, 283-289.

Mayer, M. (2005), "Constantino el Grande: deconstrucción y construcción de un Imperio", in F. de Oliveira (coord.), Génese e Consolidação da Ideia de Europa, vol. III, O Mundo Romano, Coimbra, 203-230.

Mayer, M. (2007a), "La presenza imperiale nelle città del Picenum tra l'epoca augustea e il regno dei Severi : un primo aproccio", Studi Maceratesi 41: 27-40.

Mayer, M. (2007b), "Las dedicatorias a miembros de la domus Augusta julio-claudia y su soporte: una primera aproximación”, in G. Paci (ed.), Contributi all'epigrafia del'età augustea. Actes de la XIII' Rencontre francoitalienne sur l'épigraphie du monde romain, Tivoli, 171-199

Mayer, M. (2008), "Sila y el uso político de la epigrafía", in M. Caldelli, G. L. Gregori, S. Orlandi (eds.), Epigrafia 2006. Atti della XIVerencontre sur l'épigraphie in onore di Silvio Panciera con altri contributi di colleghi, allievi e collaboratori, Roma, 121-135.

Mayer, M. (2009), "Los honores recibidos por la familia de Marco Aurelio en la parte oriental del imperio romano: ¿̨cambio o continuidad en el culto dinástico?", in A. Martínez Fernández (ed.), Estudios de Epigrafía Griega, La Laguna, 277-294.

Mayer, M. (2010), "La presència de la dinastia antonina a Tarraco", in Studia Celtica Classica et Romana Nicolae Szabó septuagesimo dicata, Budapest, 159-167.

Mayer, M. (2015), "La epigrafia y el Augusteum de Narona", in G. Zecchini (ed.), L 'Augusteum di Narona. Atti della Giornata di Studi. Roma 31 maggio 2013, (Centro ricerche e documentazione sull' antichità clàssica, monografie, 3 7), Roma, pp. 19-41.

McCrum, M., Woodhead, A.G. (1961), Select Documents of the Principates of the Flavian Emperors Including the Year of Revolution, A.D. 68-96, Cambridge.

Mednikarova, I. (2003), "The accusative of the name of the deceased in Latin and Greek epitaphs", ZPE 143: 117-134.

Meiggs, R. (1972), The Athenian Empire, Oxford.

Melani, V., Vergari, M. (1985), Profilo di una città etrusca Roselle, Pistoia.

Melchor Gil, E. (1992), "Sistemas de financiación y medios de construcción de la red viaria hispana”, Habis, 23: 121-137.

Melchor Gil, E. (2010), "Homenajes estatutarios e integración de la mujer en la vida pública municipal de las ciudades de la Bética", in F. J. Navarro (ed.), Pluralidad e integración en el Mundo Romano, Pamplona, 221-245. 
Mellor, R. (1975), ӨEA P $\Omega$ MH the Worship of the Goddess Roma in the Greek World, Göttingen.

Mellor, R. (1981), “The Goddess Roma”, in $A N R W$ II 17. 2, Berlin, New York, 950-1030

Menegazzi, L. (1995), Il manifesto italiano (prima ed. 1974), Milano.

Merêa, P. (1929), História de Portugal, Vol. II. Coimbra.

Merêa, P. (1941), Suárez, Grácio, Hobbes, Coimbra.

Mesnard, P. (1977), Essor de la philosophie politique au XVIe Siècle, Paris.

Messerschmidt, W. (2003), Prosopopoiia: Personifikationen politischen Charakters in spätklassischer und hellenistischer Kunst, Köln.

Michelini, A. N. (1994), "Political themes in Euripides' Suppliants", AJPh 115. 2: $219-252$.

Millar, F. (1968), "Local cultures in the Roman Empire: Libyan, Punic and Latin”, JRS 58: 126-134.

Millar, F. (1993), The Roman Near East 31 BC-337 AD, London.

Millar, F. (2006), A Greek Roman Empire, Power and belief under Theodosius II 408-450, Berkeley.

Minerath, R. (1996), Histoire des Conciles, Paris.

$M L H=$ J. Untermann, J. (1975-2000), Monumenta linguarum Hispanicarum, $\mathrm{I}-\mathrm{V}$, Wiesbaden.

Moggi, M. (1976), I sinecismi interstatali greci, Pisa.

Moncada, C. (1947), Filosofia do direito e do estado, I, Coimbra.

Monfrin, J. (1964), "Humanisme et traductions au Moyen Age", in L'Humanisme médieval dans les littératures romanes du XIIe au XIVe siècle (Actes du Colloque organisé par le Centre de Philologie et de Littératures romanes de l'Université de Strasbourg), Paris.

Monteiro, N., d'Encarnação, J. (1993-1994), “A propósito de uma inscrição latina em Santiago da Guarda (Ansião)", Conimbriga 32-33: 303-311.

Moretti, G. (2007), "Patriae trepidantis imago. La personificazione di Roma nella Pharsalia fra ostentum e disseminazione allegorica", Camenae 2: 1-17

Morrison, A. D. (2007), The Narrator in Archaic Greek and Hellenistic Poetry, Cambridge.

Mosley, D. J. (1965), "The Size of Embassies in Ancient Greek Diplomacy”, ТРАРЬA: 255-266.

Mosley, D. J. (1972), "Envoys and diplomacy in Ancient Greece”, Historia 22: 1-97.

Mossé, Cl. (1970), La colonisation dans l'Antiquité, Paris, 27-99. 
Mullen, A. (2007), “Linguistic evidence for 'romanization': continuity and change in Romano-British onomastics: a study of the epigraphic record with particular reference to Bath", Britannia 38: 35-61.

Muñoz, V. (2005), "La interpretatio romana del dios prerromano Bandue", Veleia 22: $145-152$.

Munro, J.A.R. (1926), “Xerxes' Invasion of Greece”, in The Persian Empire and the West, Cambridge Ancient History, Vol. IV, Cambridge, 268-316.

Nascimento, A. A. (1990), "Poggio e o seu interesse por códices de Alcobaça", Revista da Faculdade de Letras de Lisboa 13-14: 37-40.

Nascimento, A. A. (1993), "As librarias dos príncipes de Avis", Biblos. Revista da Faculdade de Letras (Coimbra). Actas do Congreso Comemorativo do $6^{\circ}$ Centenário do Infante D. Pedro (25 a 27 de Novembro de 1992) 69: 265-287.

Nascimento, A. A. (1995), "La réception des auteurs classiques dans l'éspace cultural portugais: une questione ouvert", in C. Leonardi, B. Munk Olsen (eds.), The Classical Tradition in the Middle Ages and Renaissance, Spoleto, 47-56.

Nascimento, A. A. (1997), "Traduzir, verbo de fronteira nos contornos da Idade Média”, in C. Almeida Ribeiro, M. Madureira (eds.), O género do texto medieval, Lisboa, 113-138.

Nascimento, A. A. (1999), Cister. Os documentos primitivos. No 9.० Centenário da fundação de Cister (1999). Introdução, tradução e notas de Aires A. Nascimento, Lisboa.

Navarro Caballero, M. (2003), "Mujer de notable: representación y poder en las ciudades de la España imperial”, in S. Armani, B. Martineau-Hurlet, A. U. Stylow, (eds.), Acta antiqua Complutensia IV. Epigrafía y sociedad en Hispania durante el Alto Imperio: estructuras sociales, Alcalá de Henares, 119-127.

Nemeti, S. (1998), "Cultul lui Sucellus-Dis Pater şi al Nantosueltei-Proserpina în Dacia romană”, EphemNapoc 8: 95-121.

Neumann, G., Untermann, J. (eds.) (1980), Die Sprachen im Römischen Reich der Kaiserzeit. Beihefte der Bonner Jabrbücher 40, Bonn.

Nicosia, F. (ed.) (1990), Un decennio di ricerche a Roselle. Statue e ritratti, Firenze.

Nunes, E., Albuquerque, M. (1968), "Parecer do doutor 'Valasco di Portogallo' sobre o beneplácito régio (Florença, 1954)”, in V. Rau (ed.), Do tempo e da bistoria, Lisboa, t. 2, 97-139.

Ober, J. (1989), Mass and Elite in Democratic Athens. Rhetoric, Ideology, and the Power of the People, Princeton.

Odiot, T. (2004), "Le site du Molard à Donzère", in Brun, J.-P., Poux, M., Tchernia, A. (eds.), Le vin. Nectar des Dieux. Génies des Hommes, Gollion, 202-203. 
Oelmann, F. (1914), Die Keramik des Kastells Niederbieber, Frankfurt.

Ohly, D. (1976), Die Aegineten: die Marmorskulpturen des Tempels der Aphaia auf Aegina. (a) I. Die Ostgiebelgruppe. München. (b) II. Die Westgiebelgruppe. III. Altarplatzgrupen, Akrotere, etc, München.

Olteanu, T. (2008), "El culto a Victoria y la interpretatio indígena en el Occidente de Hispania, Gallia y el norte de Britania", BVallad 74: 197-224.

Ors, A. de (1953), Epigrafia juridica de la España romana, Madrid.

Pacaut, M. (1993), Les moines blancs. Histoire de l'Ordre de Cîteaux, Paris.

Pallottino, M. (1952), "El problema de las relaciones entre Cerdeña e Iberia en la antigüedad prerromana", Ampurias 14: 137-155.

Panciera, S. (2003), "Umano, sovraumano o divino? Le divinità augustee e l'imperatore a Roma", in L. de Blois, P. Erdkamp, O. Hekster, G. De Kleijn, S. Mols, (eds.), The Representation and Perception of Roman Imperial Power. Proceedings of the Third Workshop of the International Network Impact of Empire (Roman Empire c. 200 B.C. - A.D. 476), Amsterdam, 219-239.

Paparelli, G. (1973), Feritas, humanitas, diuinitas. L'essenza umanistica del Rinascimento, Napoli.

Parker, V. (1988), "Túpavvoc. The semantics of a political concept from Archilochus to Aristotle", Hermes 126. 2: 145-172.

Patillon, M. (ed.) (2002), Pseudo-Aelius Aristide, Arts rhétoriques, Paris.

Pekary, T. (1968), Untersuchungen zu den römischen Reichsstraßen, Bona.

Pellegrini, D. P. M. (2003), Le Grandi Storie dell'Auto, vol. 2, Alfa Romeo, 35-35.

Pelling, Ch. (2002), "Speech and action: Herodotus' Debate on the Constitutions", PCPhS 48: 123-158.

Peña Cervantes, Y. (2010), Torcularia. La producción de vino y aceite en Hispania. Catálogo de yacimientos analizados en cedé (Sèrie documenta 149), Tarragona.

Pensa, M. (1979), "Genesi e svilupo dell'arco onorario nella documentazione numismática”, Studi sull'Arco Onorario Romano, Roma, 19-27.

Peres, D. (1952), História de Portugal, II, Porto.

Pérez Martin, A. (1979), Proles Aegidiana. I. Introducción. Los Colegiales desde 1368 a 1500 , Bolonia.

Pérez Martin, A. (1999), Españoles en el Alma Mater Studiorum. Profesores hispanos en Bolonia (de fines del siglo XII a 1799), Murcia.

Pérez Ruiz, F. (1984), "El justo es feliz y el injusto desgraciado, justicia y felicidad en la República de Platon", Pensamiento 40, 159: 257-295.

Petrarca, F. (1581), Francisci Petrarchae Florentini Opera. Basileae, per Sebastianum Henricpetri. 
Petrarca, F. (1942), Epistolae familiares, in V. Rossi (ed.), Le Familiari, Firenze.

Petri, Ch. (1989), 'La politique de Constance II: un premier 'césaropapisme' ou l'imitatio Constantini?", in A. Dihle (coord.), L'église et l'empire au IV siècle, Genève, 113-178.

Pfeiffer, R. (1949-1951), Callimachus, 2 vols., Oxford.

Pflaum, H.G. (1976), Inscriptions latines de l'Algérie, t. II, vol. II, Inscriptions de la Confédération cirtéenne, de Cuicul et de la tribu des Suburbures, Alger.

Pflug, H. (1941), As auto-estradas do Reich, Berlim.

Pharr, C. et alii (2008), The Theodosian Code and Novels and the Sirmondian Constitution. Translation, commentary and bibliography, Union (NJ).

Piana, C. (1976), Nuovi documenti sull'Universitá di Bologna e sul Collegio di Spagna,I-II, Bolonia, Zaragoza.

Pick, B. (1898), Die antiken Münzen Nordgriechenlands I, 2. Die antiken Münzen von Dacien und Moesien, Berlin.

Piganiol, A. (1972, 2a ed.), L'empire chrétien, Paris.

Pina, R. de (1977), Chronica do Senhor Rey D. Affonso V, cap. CXXV "Das feiçoões custumes e virtudes do Yfante Don Pedro”, in M. L. de Almeida (Intro. e Revisão), Crónicas de Rui de Pina, Porto.

Pinheiro Futre, M. P. (2006), "Do Mito à Utopia: viagem ao mundo do imaginário grego" in Actas do V Congresso da APEC-Antiguidade Clássica e nós: Herança e Identidade Cultural, Braga, 569-581.

Pinho, S. T. (1999), "Os Príncipes de Avis e o Pré- Humanismo Português", in Raizes Greco-Latinas da Cultura Portuguesa. Actas do I Congresso da APEC, Coimbra, 99-133.

Pinto, Frei H. (1952), "Diálogo da justiça”, in Imagem da vida cristã, I, Lisboa.

Pippidi, D. M. (1971), I Greci nel Basso Danubio dall'età arcaica alla conquista romana, Mailand.

Pirling, R. (1993), "Ein Trierer Spruchbecher mit ungewöhnlicher Inschrift aus Krefeld-Gellep", Germania 71: 387-404.

Podlecki, A. J. (1976), “Athens and Aegina”, Historia 25.4: 396-413.

Poenaru Bordea, G. (1979), "Les statères ouest-pontiques de type Alexandre le Grand et Lysimaque”, RBNS 125: 37-51.

Prag, J. R. W. (2002), "Epigraphy by numbers: Latin and the epigraphic culture in Sicily", in A. E. Cooley (ed.), Becoming Roman, Writing Latin? Literacy and Epigraphy in the Roman West. JRA Suppl. Ser. 48: 15-31.

Preda, C., Popescu, E., Diaconu, P. (1962), "Săpăturile arheologice de la Mangalia (Callatis)", Materiale 8: 439-455.

Pressouyre, L. (1990), Le rêve cistercien, Paris. 
Price, S. R. F. (1984), Rituals and Power. The Roman Imperial Cult in Asia Minor, Cambridge.

Privitera, G. A. (1988), "Pindaro, Nem. III 1-5 e l'acqua di Egina”, QUCC 58: 63-70.

Puerta Torres, C. (1995), Los miliarios de la Vía de la Plata, 1-2, Madrid.

Quadrino, D. (2007), Una nuova iscrizione onoraria di Adriano e il Sebasteion di Kestros in Cilicia Tracheia, Tivoli.

Radnoti Alföldi, M., Rasbach, G. (1999), "Zur Frage der interpretatio Romana“, in Festschrift für Günter Smolla, Wiesbaden, 597-605.

Raepsaet-Charlier, M. Th. (1975), "La datation des inscriptions latines dans les provinces occidentales de l'Empire Romain d'après les formules " In $\mathrm{H}$ (onorem) D(omus) D(ivinae) » et «Deo, Deae »", in ANRW II 3: 232-282.

Raepsaet-Charlier, M. Th. (2005), "Les sacerdoces des femmes sénatoriales sous le Haut-Empire", in M.-F. Baslez, F. Prévot (eds.), Prosopographie et histoire religieuse. Actes du colloque tenu en l'Université Paris XII-Val de Marne le 27 E 28 octobre 2000, Paris, 283-304.

Ramalho, A. C. (1985), Latim Renascentista em Portugal (Antologia), Coimbra.

Rapp, Cl. (2005), Holy Bishops in Late Antiquity, The nature of Christian Leadership in an age of transition, Berkeley.

Rau, V. (1969), "Italianismo na cultura jurídica portuguesa do século XV", Revista Portuguesa de História 12.1: 185-206.

Rau, V. (1973), "Studenti ed eruditi portoghesi in Italia nel secolo XV", Estudos Italianos em Portugal 36: 7-73.

Rawlinson, H. G. (1916), Intercourse between India and the Western World from the Earliest Times to the Fall of Rome, Cambridge.

Rebelo, D. L. (1951), Do governo da republica pelo rei (de republica gubernanda per regem), reprodução fac-similada da edição de 1496, Introdução e notas de A. M. de Sá, Lisboa.

Rebelo, L. de S. (1983), A concep̧̣ão do poder em Fernão Lopes, Lisboa.

Rebuffat, R. (2007), "Pour un corpus des bilingues punico-libyques et latinolibyques", in M. H. Fantar (ed.), Osmose etnho-culturelle en Méditerranée, Tunis, 183-242.

Regra do Patriarca S. Bento (1992), Edições “Ora \& Labora”, Singeverga.

Rhodes, P. J. (1993), A Commentary on the Aristotelian ATHENAION POLITEIA, Oxford.

Rhodes, P. J. (2006), A History of the Classical Greek World 478-323 BC, Molden. RIB = Collingwood, R. G. (1965), The Roman inscriptions of Britain. I. Inscriptions on stone, Oxford. 
RIG = P.-M. Duval (ed.), Recueil des inscriptions gauloises, Paris 1985-. I: M. Lejeune, Textes gallo-grecs, 1985; II.1: M. Lejeune, Textes gallo-étrusques. Textes gallo-latins sur pierre, 1988; II.2: P.-Y. Lambert, Textes gallo-latins sur instrumentum, 2002; III: P.-M. Duval y G. Pinault, Les calendriers (Coligny, Villards d'Héria), 1988; IV: J.-B. Colbert de Beaulieu y B. Fischer, Les légendes monétaires, 1998.

Ripollés, P. P. (2004), "Coinage and identity in the Roman provinces: Spain", in Ch. Howgego, V. Heuchert, A. Burnett (eds.), Coinage and identity in the Roman provinces, Oxford, 79-93.

Ripollés, P. P., Velaza, J. (2002), "Saguntum, colonia latina”, ZPE 141: 285-294.

Rodgers, B. (1989), “The Metamorphosis of Constantine”, CQ 39.1: 233-246.

Rodrigues, M. A. (1993), "O infante D. Pedro e a Universidade”, Biblos. Revista de Faculdade de Letras (Coimbra). Actas do Congreso Comemorativo do $6^{\circ}$ Centenario do Infante D. Pedro (25 a 7 de Novembro de 1992) 69: 345362.

Rodrigues, N. S. (2007), "Entre Europa e Io: elementos orientais na arte grega arcaica e clássica", in J. A. Ramos, L. M. Araújo, A. Ramos dos Santos (eds.), Arte Pré-Clássica. Colóquio Comemorativo dos Vinte Anos do Instituto Oriental da Faculdade de Letras da Universidade de Lisboa, Lisboa, 323346.

Rodríguez, P., Díez de Pinos, E. (2014), "Nueva inscripción celtibérica en piedra de E1 Pueyo de Belchite (Zaragoza)", Palaeohispanica 14: 245-262.

Rodríguez Colmenero, A., Ferrer Sierra, S., Álvarez Asorey, R. (2004), Miliários e outras inscricións viarias romanas do noroeste hispánico. Santiago de Compostela.

Rocha Pereira, M. H. (1981), "O mais antigo texto europeu de teoria política", Nova Renascença 1: 364-370.

Rocha Pereira, M. H. (1990), “O 'Diálogo dos Persas’ em Heródoto”, Estudos Portugueses. Homenagem a António José Saraiva, Lisboa, 351-362.

Rocha Pereira, M. H. (2003), Hélade. Antologia da Cultura Grega, Asa, Porto.

Rocha Pereira, M. H. (2008, 8a ed.), Sófocles: Antígona, Coimbra.

Roha Pereira, M. H. (2009, 10ª ed.), Hélade, Lisboa, Guimarães.

Rocha Pereira, M. H. (2012), Estudos de História da Cultura Clássica, vol.1 Cultura Grega, Lisboa.

Roldán Hervás, J. (1975), Itineraria Hispana. Fuentes antiguas para el estudio de las vías romanas en la Peninsula Ibérica, Madrid.

Röllig, W. (1980), “Das Punische im Römischen Reich”, in G. Neumann, J. Untermann (eds.), Die Sprachen im Römischen Reich der Kaiserzeit. (Bonner Jabrbücher des Rheinischen Landesmuseums in Bonn im Landschaftsverband 
Bibliografia

Rheinland und des Vereins von Altertumsfreunden im Rheinlande 40), Köln, 285-299.

Romano, E. (2006-2009), "Le tombe "a cupa" in Italia e nel Mediterraneo. Tipologia architettonica, committenza e rituale”, StClOr 52: 149-219.

Romilly, J. de (1959), "Le classement des constitutions d'Hérodote à Aristote", REG 72: 81-99.

Rose, C. B. (1997), Dynastic Commemoration and Imperial Portraiture in the Julio-Claudian Period, Cambridge.

Rosenthal, F. (1936), Die Sprache der palmyrenischen Inschriften und ibre Stellung innerhalb des Aramäischen, Leipzig.

Rosivach, V. J. (1977), "Earthborns and Olympians: the parodos of the Ion", CQ 27. 2: 284-294.

Rosivach, V. J. (1988), "The Tyrant in Athenian Democracy", QUCC 59: 43-57.

Rossillon, Ph. (ed.) (1995), Atlas de la langue française, Paris.

Rossiter, J. J. (1978), Roman Farm Buildings in Italy (BAR int. Ser. 52), Oxford.

Rössler, O. (1980), "Libyen von der Cyrenaica bis zur Mauretania Tingitana", in G. Neumann, J. Untermann (eds.), Die Sprachen im Römischen Reich der Kaiserzeit. (Bonner Jabrbücher des Rheinischen Landesmuseums in Bonn im Landschaftsverband Rheinland und des Vereins von Altertumsfreunden im Rheinlande 40). Köln, 267-284.

Rubenstein, L. (2004), "Ionia", in M. H Hansen, T. H. Nielsen (eds.), An Inventory of Archaic and Classical poleis, Oxford, 1053-1107.

Rucquoi, A. (2003), "Rois et princes portugais chez les auteurs castillans du $\mathrm{XV}^{\mathrm{e} m e}$ siécle», Península. Revista de Estudos Ibéricos. Entre Portugal e Espanha. Relaçôes Culturais (sécolos XV-XVIII). In Honorem Jose Adriano de Freitas Carvalho, 0: 39-51.

Ruggini, L. C. (1989), "Felix Temporum Reparatio", in A. Dihle (coord.), Realtà socio-economiche in movimento durante un ventennio di regno (Costanzo II Augusto, 337-361 d.C.), L'église et l'empire au IV siècle, Genève, 179-243.

Rüpke, J. (2005), Fasti sacerdotum. Die Mitglieder der Priesterchaften und das sakrale Funktionspersonal römischer, griechischer, orientalischer und jüdischchristlicher Kulte in der Stadt Rom von 300 v. Chr. bis 499 n. Chr., Wiesbaden.

Rusjaeva, A., Vinogradov, Ju. G., (2000), "Apollon Ietros. Herrscher von Istros”, in A. Avram, M. Babeş (eds.), Olbia, Civilisation grecque et cultures antiques périphériques. Hommages à P. Alexandrescu à son $70^{\circ}$ anniversaire, Bucarest, 229-234.

Rutishauer, B. (2012), Athens and the Cyclades. Economic Strategies 540-314 BC, Oxford. Sabbadini, R. (1905), Le scoperte dei codici latini e greci ne' secoli XIV e XV , Florencia. 
Sabbadini, R. (1914), Le scoperte dei codici latini e greci ne' secoli XIV e XV, Florencia.

Saddington, D.B. (1999), "Roman soldiers, local gods and interpretatio Romana in Roman Germany", ActaCl 42:155-169.

Salazar, A. M. (1976), "El impacto humanístico de las misiones diplomáticas de Alonso de Cartagena en la Corte de Portugal entre medievo y renacimiento (1421-31)", in A. D. Deyermond (ed.), Medieval Hispanic Studies presented to Rita Hamilton, Londres, 215-226.

Salinas, M. (1995), "Los inicios de la epigrafía en Lusitania oriental", in F. Beltrán (ed.), Roma y el naámiento de la cultura epigráfica en Occidente, Zaragoça, 281-291.

Salway, B. (2001), "Travel, Itineraria and Tabellaria", in C. Adams and R. Laurence (eds.), Travel and Geography in the Roman Empire, Londres, Nova Iorque, 22-66.

Santo Agostinho (2009 12a ed. ), A cidade de Deus, trad. de Oscar Paes Leme, 2 v., Vozes, Petrópolis, São Paulo.

Santos, M. J. A. (1998), Vida e morte de um mosteiro cisterciense. S. Paulo de Almaziva - Séculos XIII-XV, Lisboa.

Saumagne, C. (1928), "Iter populo debetur", Révue d'Histoire, de Littérature et d'Histoire Anciennes 54: 320-353.

Scheer, T. S. (2003), "The Past in na Hellenistic Present: Myth and Local Tradition", in A. Erskine (ed.), A Companion to the Hellenistic World, Oxford, 216-231.

Scheid, J. (2015), "Les Augustea et le culte des empereurs. Réflexions sur les rites célébrés dans ces lieux de culte", in P. Gros, E. Marin, M. Zink (eds.), Auguste, son époque et l 'Augusteum de Narona. Actes du colloque organisé à l'Académie des Inscriptions et Belles-Letres et l'Université Catholique de Croatie (Zagreb) 12 décembre 2014, 17-30, Paris.

Schilardi, G. (ed.) (1997), Filostrato. Immagini, Lecce.

Schmidt, R. (1980), "Die Ostgrenze von Armenien über Mesopotamien, Syrien bis Arabien”, in G. Neumann, J. Untermann (eds.), Die Sprachen im Römischen Reich der Kaiserzeit. (Bonner Jahrbücher des Rheinischen Landesmuseums in Bonn im Landschaftsverband Rheinland und des Vereins von Altertumsfreunden im Rheinlande 40). Köln, 187-214.

Schmidt, Th., Fleury, P. (2011), Perceptions of the Second Sophistic and its Times. Regards sur la seconde sophistique et son époque, Toronto, Buffalo, London.

Schwartz, J. (1960), Pseudo-Hesiodeia: recherches sur la composition, la diffusion et la disparition ancienne d'oeuvres attribuées à Hésiode, Leiden.

Scott, K. (1936), The Imperial Cult under the Flavians, Stuttgart.

Sealey, R. (1976), A bistory of Greek city-states 700 -338 B. C. Berkeley. 
Seignobos, Ch. (1969), Histoire sincère de la nation française, Paris.

Semerari, L. (2000), Aula Magna Università degli Studi di Bari, Bari.

Sergent, B. (2006), "Sucellus et le tonneau", in Anthropology of the Indo-European World and Material Culture. Proceedings of the 5th International Colloquium of Anthropology of the Indo-European World and Comparative Mythology, Budapest, 61-80.

Serra, J. C. da (1972), Academia Real das Sciencias de Lisboa, II, cap. VII, Lisboa. Sforza, W. C. (1951), “Osservazioni sul 'De nobilitate legum' di Coluccio Salutati”, in E. Castelli (ed.), Umanesimo e Scienza politica (Atti del congresso Internazionale di Studi Umanistici, Roma-Firenze, 1949), Milano.

Shapiro, H.A. (1993), Personification in Greek art: the representation of abstract concepts 600-400 b.C., Zürich.

Shaw, M. H. (1982), “The $\tilde{\eta} \theta$ os of Theseus in 'The Suppliant Women”, Hermes 110. 1: 3-19.

Shorrock, R. (2011), The Myth of Paganism: Nonnus, Dionysus and the World of Late Antiquity, Bristol.

Sigeia, L. (1970), Dialogue de deux jeunes filles sur la vie de retraite (1552), Présenté, traduit et annoté par O. Sauvage (ed.), Paris.

Sillières, P. (1990), Les voies de communication de l'Hispanie méridionale, Paris.

Silva, N. J. E. G. (1964), Humanismo e Direito em Portugal no século XVI, Lisboa.

Simón, I. (2013), Los soportes de la epigrafía paleohispánica. Inscripciones sobre piedra, bronce y cerámica, Zaragoza, Sevilla.

Siniscalco, P. (2004, 5a ed.), Il cammino di Cristo nell'Impero romano, Roma, Bari.

Slavazzi, F. (2006), "Il ciclo di relievi della Kaisersaal del ginnasio di Vedio a Efeso", in Iconografía 2005. Immagini e immaginari dell'antichità classica al mondo moderno, Roma, 235-243

Smyth, A. C. (2011), Polis and Personification in Classical Athenian Art, Leiden.

Snodgrass, A. M. (1977), Archaeology and the rise of the Greek state, Cambridge.

Snodgrass, A. M. (1980), Archaic Greece. The age of experiment, Londres.

Soares, C. (2008), Platão. O Político. Tradução do grego, introdução e notas, Lisboa.

Soares, C. (2014), “Theoria e práxis política em Heródoto”, Cuadernos de Filología Clássica: Estudios griegos e indoeuropeus 24: 57-79.

Soares, N. C. (1994), O príncipe ideal no século XVI e a obra de D. Jerónimo Osório, Coimbra.

Soares, N. C. (2002), "O infante D. Pedro e a cultura portuguesa", Biblos. Revista da Faculdade de Letras 78:107-128. 
Sodano, A. R. (1970), Porphyrii Quaestionum Homericarum Liber I, Napoli.

Solas, J. G. (2008), “Escrito sobre la ciudad”, Pensar la publicidad, II, n. 2: 37-62.

Sordi, M. (1965), Il cristianesino e Roma, Bologna.

Sordi, M. (1984), I cristiani e l'impero romano, Milano.

Soria, A. (1956), Los humanistas de la Corte de Alfonso el Magnánimo (según los epistolarios), Granada.

Sousa, D. A. C. de (1946-1954), Memória dos livros do uso del Rey D. Duarte, in Provas da história genealógica da casa real portuguesa, tomo I, liv. III, Coimbra.

Sousa, R., Fialho, M. C., Haggag, M., Rodrigues, N. S. (2013), Alexandrea ad Aegyptum: The Legacy of Multiculturalism in Antiquity, Lisboa.

Spickermann, W. (1997), "Aspekte einer neuen regionalen Religion und der Prozess der "interpretatio" im römischen Germanien, Rätien und Noricum", in Römische Reichsreligion und Provinzialreligion, Tübingen, 145-167.

Spyridakis, S. (1968), “Zeus is Dead: Euhemerus and Crete”, CJ 63: 337-340.

Stafford, E., Herrin, J. (eds.) (2005), Personification in the Greek World from Antiquity to Byzantium, Burlington.

Statuta capitulorum generalium ordinis Cisterciensis ab anno 1116 ad annum 1786 edidit Josephus M. ${ }^{\text {ia } C a n i v e z ~(1933-1941), ~} 8$ vols., Louvain.

Stefan, A. (2005), "Le titre de filius Augustorum de Maximin et Constantin et la théologie de la tétrarchie", in M.-F. Baslez, F. Prévot (eds.), Prosopographie et histoire religieuse. Actes du colloque tenu en l'Université Paris XII-Val de Marne le 27 Eं 28 octobre 2000, Paris, 329-349

Stefani, G. (1986), "I cippi a botte della provincia Sardinia”, Nuovo bullettino Archeologico Sardo 3: 115-160.

Stefani, G. (1988), "Cippi a botte nella basilica di S. Saturnino a Cagliari”, Quaderni della Soprintendenza archeologica per le province di Cagliari e Oristano 5: 167-175.

Stegmann, A. (1977), "La place de la praxis dans la notion de 'raison d'État' ", in Théorie et pratique politiques à la Renaissance, Paris.

Steinbrecher, M. (1985), Der Delisch-Attischen Seebund und die AthenischSpartanischen Beziehungen in der Kimonischen Ära (478/77-462/1), Berlin.

Stemmer, K (ed.) (1995), Standorte - Kontext und Funktion antiker Skulptur, Berlin.

Sterckx, C. (2008), "Sucellos et le casque d'Hadès", in Philomythia. Mélanges offerts à Alain Moreau, Monts, 223-229.

Stern, J. (1996), Palaephatus. Peri Apiston: On Unbelievable Tales, Wauconda. 
Stern, J. (1999), "Rationalizing Myth: Methods and Motives in Palaephatus" in R. Buxton, R. (ed.), From Myth to Reason? Studies in the Development of Greek Thought, Oxford, 215-222.

Stewart, A. (1990), Greek Sculpture: an exploration, New Haven, Yale.

Storey, I. C. (2003), Eupolis poet of old comedy, Oxford.

Stowe Mead, G. R. (1901), Apollonius of Tyana, the Philosopher-Reformer of the First Century A.D., London.

Strassler, R. B. (ed.) (2007), Landmark Herodotus: The Histories, New York.

Strassler, R.B. (ed.) (2009), Landmark Herodotus: The Histories, New York.

Strootman, R. (2010), "Literature and the Kings", in Clauss, J., Cuypers, M. (eds.), A Companion to Hellenistic Literature, Malden, Oxford, 30-45.

Suberbiola Martínez, J. (1987), Nuevos concilios hispano-romanos de los siglos III y IV. La colección de Elvira, Málaga.

Szabó, Á. (2007), Daciai papság, Budapest.

Szabó, Á. (2008), "Sulla questione dello statuto giuridico dei sacerdoti provinciali durante il principato. Studio preliminare”, Iustum Aequum Salutare 4: 71-81.

Tamerl, I. (2008), Das Holzfass in der römischen Antike mit einer Studie zu Fassfunden in Raetien, Diplomarbeit presso l'Università di Innsbruck, consultabile presso la Universitäts- und Landesbibliothek Innsbruck DG43696.

Tate, J. (1927), “The Beginnings of Greek Allegory”, CR 41.6: 214-215.

Tchernia, A. (1986), Le vin de l'Italie romaine. Essai d'bistoire économique d'après les amphores (BEFAR 261), Rome.

Teive, D. de (1786), Epodos Que Cont'em Sentenças Uteis A todos os Homens, A's quaes se acrescentão Regras para a boa educação de hum principe. Trad. no vulgar em verso solto por Francisco de Andrade (conforme à ed. de Lisboa, 1565), Lisboa, Na Of. Patr. de Francisco Luiz Ameno.

Temporini, H. (1978), Die Frauen am Hofe Trajans. Ein Beitrag zur Stellung der Augustae im Principat, Berlin, New York.

Thomson de Grummond, N. (2006), Etruscan Myth. Sacred History, and Legend, Philadelphia.

Tomlin, R. S. O. (1987), "Was ancient British Celtic ever a written language? Two texts from Roman Bath", Bulletin of the Board of Celtic Studies 34: 18-25.

Topál,J. (1990), “Der Import der sogenannten Moselweinkeramik in Pannonien”, ReiCretActa 27-28: 177-184.

Tortorici, E. (1975), Castra Albana. Forma Italia, Regio I, Roma.

Touchard, J. (1959), Histoire des idées politiques, I. Paris [trad. port. Lisboa, 1970]. 
Tranoy, A. (1981), La Galice romaine, Paris.

Tuchelt, K. (1981), "Zum Problem Kaisareion-Sebasteion. Eine Frage zu den Anfängen des römischen Kaiserkultes”, MDAI, 31 : 167-186.

Ulbert, G. (1959), "Römische Holzfässer aus Regensburg”, Bayerische Vorgeschichtsblätter 24: 6-29.

Ullman, B. L. (1963), The humanism of Coluccio Salutati, Padova.

Ullmann, W. (1980), Radici del Rinascimento (tr. ital.), Roma, Bari.

Unz, R.K. (1985), "The Surplus of the Athenian phoros", GRBS 26: 21-42.

Ureña Prieto, M. H. (2001), Dicionário de Literatura Grega, Lisboa.

Valiño, A. (1999), "La cerveza en las fuentes romanas. Base textual y fijación de su importancia”, AncHistB 13: 60-71.

Van Haeperen, F. (2002), "Le collège pontifical (3ème s. a.C.-4ème s. p.C.)", Études de Philologie, d'Archéologie et d'Histoire Anciennes 39: 11-42.

Varner, E.R. (2004), Mutilation and transformation. Damnatio memoriae and Roman Imperial Portraiture, Leiden, Boston.

Várzeas, M. I. O. (2013), "Callimachus and the New Paths of Myth”, in R. Sousa et alii (coord.) Alexandrea ad Aegyptom: the legacy of multiculturalismo in antiquity. Lisboa.

Velaza, J. (2003), "Epigrafía ibérica emporitana: bases para una reconsideración”, Palaeohispanica 3: 179-192.

Velaza, J. (2003a), "Las inscripciones monetales”, in P. P. Ripollés, M. del M. Llorens, Arse-Saguntum. Historia monetaria de la ciudad y su territorio, Sagunto, 121-148.

Velaza, J. (2009), “Epigrafía y literacy paleohispánica en territorio vascón”, Palaeohispanica 9: 611-622.

Vergerio, P. P. (1934), “Epistolario di Pier Paolo Vergerio”, in L. Smith (ed.), Fonti per la storia d'Italia, vol. 74, Roma, 436-445.

Vierneisel, K., Zanker, P. (1979), Die Bildnisse des Augustus: Herrscherbild und Politik in kaiserlichen Rom, München.

Villar, F., Pedrero, R. (2001), “Arroyo de la Luz III”, Palaeohispanica 1: 235274.

Vinogradov, J. G. (2000), "Heilkundige Eleaten in den Schwarzmeergründungen”, in M. Dreher (ed.), Bürgersinn und staatliche Macht. Festschrift für Wolfgang Schuller zum 65. Geburtstag, Konstanz, 133-149.

Vittinghoff, F. (1951), Römische Kolonisation und Bürgerrechtspolitik unter Caesar und Augustus, Wiesbaden.

Vives, J., Marín, T., Martínez, G. (1963), Concilios visigóticos e hispano-romanos, Madrid, Barcelona. 
Voragine, T. (2004), Legenda Aurea. Apresentação do Cardeal Dom José Saraiva Martins e introdução do Doutor Aníbal Pinto de Castro. Tomo Segundo, Porto.

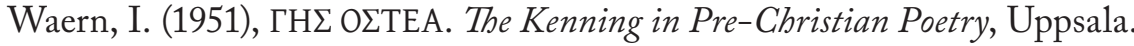

Wallace, M. B., Figueira, T. J. (2010), "Notes on the Island Phoros", ZPE 172: 65-69.

Wallace-Hadrill, A. (2005), "Mutatas formas: The Augustan Transformation of Roman Knowledge", in K. Galinsky (ed.), The Cambridge Companion to the Age of Augustus, Cambridge, 55-84.

Wallinga, H. T. (2005), Xerxes' Greek Adventure. The Naval Perspective, Leiden.

Walter, H. (1993), Ägina: die archäologische Geschichte einer griechischen Insel, München.

Walters, K. R. (1981), "Four Hundred Athenian Ships at Salamis?”, RbM 124: 199-203.

Wankel, H. (1983), "Thukydides 1,74,1 und die Schiffszahlen von Salamis," ZPE 52: 63-66.

Wells, J. (1923), Studies in Herodotus, Oxford.

Wesseling, P. (ed.) (1735), “Itinerarium Antonini Augusti”, Vetera Romanorum Itineraria, Amesterdão.

West, M. L. (1985), The Hesiodic Catalogue of Women: Its Nature, Structure, and Origins, Oxford.

Westrem, S. D. (2001), The Hereford Map. A Transcription and Translation of the Legend with Commentary, Turnhout.

Williams, D. (1987), "Aegina, Aphaia-Tempel XI: the pottery from the second limestone temple and the later history of the sanctuary", $A A$ : 629-680.

Williamson, G. (2004), "Aspects of identity", in C. Howgego, V. Heuchert, A. Burnett (eds.), Coinage and Identity in the Roman Provinces, Oxford, 19-27.

Winiarczyk, M. (2013), The «Sacred History» of Eubemerus of Messene, Berlin.

Witschel, Chr. (1995a), "Römische Tempelkultbilder und Römische Kaiserstatuen als Tempelkultbilder", in K. Stemmer, (ed.), Standorte. Kontext und Funktion antiker Skulptur; Ausstellungskatalog Abgußsammlung, Berlin, 250-265.

Witschel, Chr. (1995b), "Statuen auf römischen Platzanlagen unter besonderer Berücksichtigung von Timgad (Algerien)", in K. Stemmer (ed.), Standorte. Kontext und Funktion antiker Skulptur; Ausstellungskatalog Abgußsammlung, Berlin, 332-358.

Witschel, Chr. (2002), "Zum Problem der Identifizierung von munizipalen Kaiserkultstätten”, Klio 84: 114-124. 
Wlosok, A. (ed.) (1978), Römischer Kaiserkult, Darmstadt.

Wojciechowski, P. (2002), "Il culto di Beleno ad Aquileia romana. Origini, interpretatio Romana e la cosiddetta rinascita celtica", in Gli echi della terra. Presenze celtiche in Friuli. Dati materiali e momenti dell' immaginario. Convegno di studi, Castello di Gorizia, 5 - 7 ottobre 2001, Pisa, 29-35.

Woodard, R. (ed.) (2007), The Cambridge Companion to Greek Mythology, Cambridge.

Woodhead, A. G. (1962), The Greeks in the West. London. (Trad. port., Os Gregos no Ocidente).

Woolf, G. (1996), "Monumental writing and the expansion of the Roman society in the Early Empire", JRS 86: 22-39.

Woolf, G. (2002), "Afterword. How the Latin West was won”, in A. Cookey (ed.), Becoming Roman, writing Latin? Literacy and Epigraphy in the Roman West, JRA Suppl. Ser. 48: 181-188.

Yatromanolakis, Y. (2005), "Poleos erastes. The Greek city as the beloved", in E. Stafford, J. Herrin (eds.), Personification in the Greek World: From Antiquity to Byzantium, London, 267-284.

Young, T. Cuyler (1980), “480/479 B.C. - A Persian Perspective”, Iranica Antiqua 15: 213-39.

Zamora, J. A. (2005), "La práctica de escribir entre los primeros fenicios peninsulares y la introducción de la escritura entre los pueblos paleohispánicos”, Palaeohispanica 5: 155-19.

Zanichelli, G. Z. (2005), "Il mito di Troia nell'immaginario medievale”, in G. Burzacchini (coord.), Troia tra realtà e leggenda, Parma.

Zanker, P. (1983), Provinzielle Kaiserporträts. Zur Rezeption der Selbstdarstellung der Princeps, München.

Zaoli, G. (1912), “Lo Studio bolognese e papa Martino V”, Studi e Memorie per la storia dell'Università di Bologna I - série v. III: 105-188.

Zecchini, G. (ed.) (2015), L'Augusteum di Narona. Atti della Giornata di Studi. Roma 31 maggio 2013, (Centro ricerche e documentazione sull'antichità clàssica, monografie, 37), Roma.

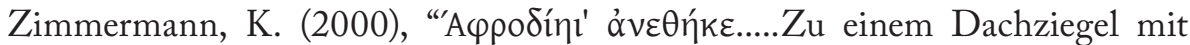
Votivinschrift", in A. Avram, M. Babeş (eds), Olbia, Civilisation grecque et cultures antiques périphériques. Hommages à $P$. Alexandrescu à son $70^{\circ}$ anniversaire, Bucarest, 239-251.

Zurara, G. E. de (1972), Chronica do Conde Dom Pedro de Meneses, II, Lisboa. 